\title{
Effect of sand content on engineering properties of fly ash-slag based strain hardening
}

\section{geopolymer composites}

\author{
Yi Wang, Yansong Wang, Mingzhong Zhang* \\ Department of Civil, Environmental and Geomatic Engineering, University College London, \\ London, WC1E 6BT, UK
}

\begin{abstract}
Strain hardening geopolymer composite (SHGC) is a tailored group of sustainable highperformance fibre reinforced geopolymer composites with strain hardening behaviour and ultra-high ductility. This paper experimentally investigates the effect of fine silica sand content $(0-40 \%$ by weight of the geopolymer binder) on engineering properties of fly ash-slag based SHGC cured at ambient temperature, including workability, setting time, drying shrinkage, compressive strength, and flexural strength as well as deflection hardening behaviour that is particularly emphasised. The results indicate that all SHGC specimens exhibit deflection hardening characteristics along with large deflection and multiple microcracks distributed over the tensile side of the specimens. The widths of microcracks are within $300 \mu \mathrm{m}$ and mostly smaller than $45 \mu \mathrm{m}$. The flowability, setting time, drying shrinkage and compressive strength of SHGC reduce with the increase of sand content at early ages up to $28 \mathrm{~d}$. However, at $28 \mathrm{~d}$, the incorporation of sand up to $20 \mathrm{wt} \%$ increases the flexural strength and toughness of SHGC, but the further increase of sand content up to $40 \mathrm{wt} \%$ results in a decrease in flexural strength and toughness.
\end{abstract}

Keywords: Alkali-activated materials; Micro-silica sand; PVA fibre; Engineered geopolymer composites; Toughening mechanism

\section{Introduction}

Concrete is the most widely used construction material in the world because of its affordability, availability and exceptional strength. However, concrete is brittle and prone to cracking. In order to limit the growth of cracks and the brittleness of the plain concrete, short fibres are incorporated into cementitious materials to produce fibre reinforced cementitious composites (FRCC). Nowadays, researchers have been developing strain hardening cementitious composites (SHCC) as a tailored group of FRCC to achieve ultra-high-ductile performance [1]. Unlike FRCC, the unique characteristic of SHCC is the formation of multiple microcracks rather than a few wide cracks under tensile load.

\footnotetext{
* Corresponding author. E-mail address: mingzhong.zhang@ucl.ac.uk (M. Zhang)
} 
Albeit the superior performance of SHCC materials, typical SHCC mixes are costly and contain 2-3 times higher ordinary Portland cement (OPC) content than conventional concrete, which would make the current situation more severe that the construction industry annually uses 4.3 billion tonnes of OPC as binder for concrete and the production of 1 tonne OPC contributes $0.7-1.1$ tonne of carbon emission to global warming [2]. In recent years, an increasing number of attempts have been made to develop ultra-ductile cementitious composites with alternative binders to reduce carbon emissions.

Strain hardening geopolymer composites (SHGC), also called engineered geopolymer composites (EGC), have been considered as a promising alternative to SHCC with enhanced mechanical properties and environmental performance. Up to now, the main raw materials used to produce SHGC are industrial by-products such as fly ash (FA), ground granulated blast-furnace slag (GGBS), and silica fume (SF). A list of recent literature on SHGC is shown in Table 1, among which the particular focus has been placed on FA-based or GGBS-based SHGC. Ahmed and Ronnie [3] studied the effect of polyethylene (PE) fibre on mechanical properties of FA-based SHGC and found that the increase of PE fibre content resulted in a decrease in the compressive strength of SHGC and SHGC reinforced with 1 vol\% PE fibre exhibited the optimum strain and deflection hardening behaviour. The effect of geopolymer matrix properties on the strain hardening behaviour of FA-based SHGC was experimentally investigated by Nematollahi et al. [4] who reported that the incorporation of sand led to an increased elastic modulus, while the strain hardening behaviour of SHGC was adversely affected by the excessive use of fine and coarse sands. This was attributed to the increased fracture toughness of the matrix and first-crack strength of the composite. Ohno and Li [5] explored the feasibility of developing FA-based SHGC mortar and proposed a design methodology for SHGC by integrating three design techniques including design of experiment, micromechanical modelling and material sustainability indices, which can not only maintain a high tensile ductility but also enhance the compressive strength and material greenness [6]. The optimised SHGC presented a $43.1 \mathrm{MPa}$ improvement in compressive strength and $4.7 \%$ higher tensile ductility, but $11 \%$ reduction in embodied energy and 55\% less carbon emission compared to SHCC. Choi et al. [7] adopted hydrophobic PE fibre to produce GGBS-based SHGC, which achieved a tensile strain capacity of up to $7.5 \%$ and tensile strength of $13.06 \mathrm{MPa}$ with an average crack width of $101 \mu \mathrm{m}$. Trindade et al. [8] developed metakaolin-based SHGC reinforced with distinct natural (jute, sisal and curauá) and PVA fibres and observed that all investigated samples exhibited strain hardening behaviour with the 
formation of multiple cracks.

It is known that FA-based SHGC requires heat curing to gain early strength while GGBS-based SHGC has low workability, short setting time and large shrinkage, which may limit the large-scale and in-situ engineering applications of them [9, 10]. To address these drawbacks, an increasing number of studies have recently been undertaken to develop SHGC cured at ambient temperature made of blended FA-GGBS binders, in which GGBS plays a significant role in improving the mechanical properties of SHGC, while the workability of SHGC increases with increasing FA content $[9,10]$. Ling et al. [11] estimated the effect of slag incorporation on the mechanical properties of FAGGBS based SHGC paste and found that increasing slag content improved strength but reduced ductility. Alrefaei and Dai [12] explored the effects of additional fibres (PE and steel) on the tensile behaviour of SHGC paste and mortar and concluded that the incorporation of sand increased the compressive strength and fracture properties of geopolymer matrix but impaired the strain hardening and multiple micro-cracking behaviour of SHGC. Al-Majidi et al. [13] investigated the mechanical properties of FA-GGBS-SF based SHGC reinforced with different types of fibre (PVA, glass, straight/hooked end steel fibres) with various volume content and aspect ratios. Their experimental results indicated that SHGC reinforced with 2 vol\% PVA fibre or 2 vol\% and 3 vol\% steel fibre of 13 $\mathrm{mm}$ length led to superior deflection capacity. Batista et al. [14] produced SHGC by partially replacing metakaolin with SF and found that the addition of SF improved the flexural toughness by $170 \%$ and deformation capability in tension but reduced the demand of sodium silicate (30 wt $\%$ ), which further reduced the $\mathrm{CO}_{2}$ emissions. Although the mechanical properties of FA-GGBS based SHGC cured at ambient temperature have been increasingly studied in recent years, the effect of fine silica sand on the engineering properties including fresh and hardened properties of FA-GGBS based SHGC has not been systematically explored yet, and the deflection hardening and multiple cracking behaviour of SHGC have not been fully investigated.

This paper therefore aims to investigate the effect of fine silica sand content on the engineering properties of PVA fibre reinforced blended FA-GGBS based SHGC cured at ambient temperature. A series of tests were conducted to measure the engineering properties including workability, setting time, drying shrinkage, compressive strength, flexural strength and flexural toughness of SHGC with various sand content ranging from $0 \%$ to $40 \%$ by weight of the geopolymer binder. The influence of fine silica sand on the deflection hardening behaviour of SHGC including stress-deflection response, 
failure mode and cracking, flexural toughness and toughening mechanism was then estimated and discussed in detail. Afterwards, the optimal sand content for SHGC was proposed.

\section{Experimental Program}

\subsection{Raw materials}

In this study, low-calcium (equivalent to ASTM Class F) FA and GGBS were used as the precursors for synthesising geopolymer. Table 2 presents the chemical composition of FA and GGBS, the particle size distribution of which is illustrated in Fig. 1. FA and GGBS have average particle sizes of $53.60 \mu \mathrm{m}$ and $14.77 \mu \mathrm{m}$, and specific gravity of 2.65 and 2.9 , respectively. A mixture of sodium hydroxide $(\mathrm{NaOH} ; \mathrm{SH})$ solution with molarity of 10 and sodium silicate $\left(\mathrm{Na}_{2} \mathrm{SiO}_{3} ; \mathrm{SS}\right)$ solution with modulus $\left(\mathrm{SiO}_{2} / \mathrm{Na}_{2} \mathrm{O}\right.$ ratio) of $2.0\left(\mathrm{Na}_{2} \mathrm{O}: 15.35 \mathrm{wt} \%, \mathrm{SiO}_{2}: 29.79 \mathrm{wt} \%\right.$, water: $\left.54.86 \mathrm{wt} \%\right)$ was used as alkaline activator that was mixed with a SS/SH ratio of 2.0. It was prepared by dissolving the $\mathrm{NaOH}$ powder in the tap water, followed by the addition of $\mathrm{Na}_{2} \mathrm{SiO}_{3}$ solution. Then, the alkaline activator was stored in the cupboard overnight to allow the heat dissipation that was caused by the exothermic chemical reaction between $\mathrm{NaOH}$ and $\mathrm{Na}_{2} \mathrm{SiO}_{3}$ [11]. The modified polycarboxylate-based superplasticiser (SP) was used to improve the workability of geopolymer composites. It was reported that the addition of such type of SP by $1 \mathrm{wt} \%$ of the binder resulted in an increase of the workability of geopolymer paste by approximately $40 \%$ [27].

Fine silica sand sourced from a quarry in Cheshire, UK was used as the aggregate, which has a specific gravity of 2.65. As seen in Fig. 1, the particle size distribution of sand has the maximum and average particle size of $250 \mu \mathrm{m}$ and $148 \mu \mathrm{m}$, respectively. PVA fibre, supplied by Kuraray, was used as reinforcement because of its higher tensile strength and Young's modulus [28]. PVA fibre was coated with $1.2 \mathrm{wt} \%$ oil to control the interface properties of SHGC [29]. PVA fibre has a nominal diameter of $40 \mu \mathrm{m}$ and a length of $12 \mathrm{~mm}$. The tensile strength, Young's modulus and strain capacity of PVA fibre are $1600 \mathrm{MPa}, 41 \mathrm{GPa}$ and $6.0 \%$, respectively.

\subsection{Sample preparation}

Five SHGC mixes with $0 \%, 10 \%, 20 \%, 30 \%$, and $40 \%$ (by weight) incorporation of fine silica sand were studied here, which were denoted as SHGC0, SHGC1, SHGC2, SHGC3, and SHGC4, respectively. Table 3 shows the mix proportions of SHGC specimens, where the contents of precursors (FA and GGBS), alkaline activator, SPs and PVA fibre were determined based on the previous studies on engineering properties of FA-GGBS based geopolymer composites cured at 
ambient temperature [30-32]. Herein, the binder of SHGC mixes is composed of FA and GGBS with a FA/GGBS ratio of $0.8 / 0.2$. The activator/binder ratio was taken as 0.4 . SPs with a weight ratio to binder of $1 \%$ were added to improve the workability of fresh SHGC specimen. Short PVA fibre was incorporated with a volume fraction of $2 \%$ to the mixture. The above mix proportions were kept constant in all mixtures.

All samples were mixed using a Hobart HSM 10 and typically lasted around 8 min. Firstly, FA, GGBS and dry silica sand were added in the mixer and dry mixed for $1 \mathrm{~min}$ to obtain a homogeneous mix. Then, the alkaline activator was gradually added into the binder and mixed for $1 \mathrm{~min}$, followed by the addition of SPs to make the matrix flowable and mixed for another $1 \mathrm{~min}$. Subsequently, the PVA fibre was added gradually to avoid multifilament forms. After the mixing, the material was immediately poured into moulds and vibrated to allow the air bubble to escape and compact the SHGC. All samples were then covered with the plastic sheet to prevent water evaporation and stored in the ambient environment for $24 \mathrm{~h}$. Afterwards, the samples were demoulded and then stored in a curing room with an average temperature and relative humidity of $20 \pm 2{ }^{\circ} \mathrm{C}$ and $60 \pm 5 \%$ respectively until the age of testing.

\subsection{Testing methods}

\subsubsection{Flow table test}

Flowability of the fresh SHGC was obtained as per ASTM C1437-15 by measuring the spread diameter of fresh mortar using the flow table test. The flow mould had a dimension of 50-mm height, 70-mm top opening diameter and 100-mm bottom opening diameter $\left(D_{0}=100 \mathrm{~mm}\right)$. For each mix, the flow table test was conducted three times to obtain the average value, $D(\mathrm{~mm})$. The flow of the fresh SHGC specimen can be calculated as $\left(D-D_{0}\right) / D_{0} \times 100 \%$.

\subsubsection{Setting time test}

Setting time test was carried out according to ASTM C191-08 by measuring the penetration depth of fresh SHGC immediately after mixing using CONTROLS Vicamatic 4417 with a needle diameter of $1.13 \mathrm{~mm}$. The penetration of the Vicat needle was recorded with the intervals of $5 \mathrm{~min}$. The Vicat needle time was added to the duration of initial mixing and the first Vicat recording and considered as the setting time. The initial setting time was interpreted by the time to reach the penetration depth of $25 \mathrm{~mm}$, and the final setting time was recorded when the penetration measurement did not mark the specimen surface with a complete circular impression. 


\subsubsection{Drying shrinkage test}

Drying shrinkage test was performed on $50 \times 50 \times 280 \mathrm{~mm}$ SHGC prisms according to ASTM C490. For each test, three samples were measured to consider the variability of performance.

\subsubsection{Uniaxial compression test}

Uniaxial compression test was carried out on $50 \times 50 \times 50 \mathrm{~mm}$ cubic SHGC specimens in accordance with ASTM C109-16 at curing ages of 1, 7, and $28 \mathrm{~d}$ using a CONTROLS C4600/FR with a maximum loading capacity of $2000 \mathrm{kN}$. The loading rate of $1200 \mathrm{~N} / \mathrm{s}$ was used for all samples. For each curing age of the mixtures, three samples were tested, and the average value was used.

\subsubsection{Four-point bending test}

Four-point bending test was conducted to determine the flexural strength and evaluate the deflection hardening behaviour of SHGC according to ASTM C1609-05 using an Instron 3345 with a maximum loading capacity of $5 \mathrm{kN}$. The average values of flexural strength of three $400 \times 100 \times 20 \mathrm{~mm}$ prismatic specimens at 7 and $28 \mathrm{~d}$ of curing were obtained. The vertical displacement was measured and recorded automatically through the loading head on the machine. The loading rate of $1.6 \mathrm{~mm} / \mathrm{min}$ was used based on preliminary tests. During the test, the loading was stopped increasing when the test reached the failure criteria either when 1) the load reached $4900 \mathrm{~N}$, or 2) the deflection reached $105 \mathrm{~mm}$, or 3) the load drop reached $150 \mathrm{~N}$. Immediately after the test was stopped, images of all cracks on each sample were captured using Dino-Lite digital microscope to measure the crack number and crack width of SHGC samples. In addition, the flexural toughness was estimated when the deflection reached the nominal depth corresponding to a net deflection of $\mathrm{L} / 150$ that is $2 \mathrm{~mm}$ in this study.

\section{Results and discussion}

\subsection{Flowability}

In this study, the flowability was used to represent the workability of fresh SHGC mixtures. The SHGC mixture with higher flowability reflects better fluidity and workability and was easier for casting and compacting. Fig. 2 shows the flow values of fresh SHGC mixtures with various sand content. It can be observed that the addition of fine silica sand resulted in a gradual reduction in the flow of SHGC specimens in the fresh state. The SHGC paste without fine silica sand (SHGC0) had a flow of $68.3 \%$. The increase of sand content by $10 \mathrm{wt} \%$ (SHGC1), $20 \mathrm{wt} \%$ (SHGC2), $30 \mathrm{wt} \%$ (SHGC3), and $40 \mathrm{wt} \%$ (SHGC4) gradually reduced the flow of fresh SHGC mixtures by 7.0\%, 19.5\%, 
$41.5 \%$, and $45.5 \%$, respectively. A similar trend in workability influenced by sand content was also reported by Alrefaei and Dai [12]. According to their study, the SHGC paste without sand had better workability than the SHGC mortar containing $30 \mathrm{wt} \%$ sand, and a drop of $23 \%$ in workability of SHGC mortar incorporated with $30 \mathrm{wt} \%$ sand was observed as compared with its counterpart paste. The reduction in flowability of SHGC mixtures with the increase of sand content can be ascribed to the higher shear resistance of SHGC mixtures to flow. In addition, while adding alkaline activator into the dry mix, part of water would be restrained by sand as the adsorption layer water, resulting in the reduced content of alkaline activator solution and activator-to-binder ratio [31, 33, 34]. On the other hand, the total surface area of the sand in fresh SHGC increased with the increase of sand content [35], and required more water as the adsorption layer water, which led to the decrease of workability of SHGC mixtures with higher sand content. It should be noted that the addition of fine silica sand in fresh SHGC specimens caused difficulties in mixing, casting, and vibration.

\subsection{Setting time}

Setting time is one of important properties of SHGC, which comprises of initial setting time and final setting time depending on the rigid level of the material. In this study, setting time was used to verify the feasibility of SHGC mixtures for engineering application, because the mixture that had short setting time could lead to difficulties in casting and compaction. Fig. 3 illustrates the change in setting time against sand content. The inclusion of sand had a marginal reduction effect on the setting time of SHGC mixtures. The SHGC paste without sand (SHGC0) had initial and final setting time of 85 min and $155 \mathrm{~min}$, respectively. Compared to SHGC0, the increase of sand content by $10 \mathrm{wt} \%$ (SHGC1), $20 \mathrm{wt} \%$ (SHGC2), $30 \mathrm{wt} \%$ (SHGC3), and $40 \mathrm{wt} \%$ (SHGC4) reduced the initial setting time by $9.7 \%, 12.1 \%, 28.3 \%$, and $19.1 \%$, respectively, as well as the final setting time by $8.2 \%, 21.8 \%$, $15.5 \%$, and $22.0 \%$, respectively. This can be attributed to the decrease of alkaline activator to binder ratio with increasing sand content. Moreover, the reduction of alkaline activator-to-binder ratio further caused the in insufficient alkaline activator for dissolution of geopolymer binder and then the reduced level of geopolymerisation $[31,36,37]$. However, the reaction between sodium hydroxide and micrometric particles of silica sand generally requires external conditions such as heating and pressurisation, therefore can be negligible in this study [38].

\subsection{Drying shrinkage}

Drying shrinkage is the net volumetric contraction caused by the high capillary pressures generated 
by the loss of water, which could result in cracking in the microstructure [39, 40]. Fig. 4 shows the drying shrinkage of SHGC specimens with various sand content ranging from $0 \%$ to $40 \%$ by weight of the geopolymer binder. The drying shrinkage of SHGC specimens was effectively reduced with the increase of sand content. At the early ages, the SHGC specimens without sand (SHGC0) exhibited the most rapid drying shrinkage rate. The incorporation of sand up to $40 \mathrm{wt} \%$ gradually reduced the drying shrinkage rate of SHGC specimens with the lowest drying shrinkage rate observed in SHGC with $40 \mathrm{wt} \%$ sand (SHGC4). A similar finding was reported in a previous study [41]. The rapid drying shrinkage rate of SHGC specimens at early ages can be associated with the rapid reduction of internal relative humidity due to the loss of water from the surface of specimens, which was freshly formed [41]. At 28 d, the SHGC specimens without sand (SHGC0) showed the highest drying shrinkage. When the sand content was increased by $10 \mathrm{wt} \%$ (SHGC1), $20 \mathrm{wt} \%$ (SHGC2), $30 \mathrm{wt} \%$ (SHGC3), and $40 \mathrm{wt} \%$ (SHGC4), the drying shrinkage of SHGC specimens dropped by 10.4\%, 19.5\%, 26.5\%, and $56.1 \%$, respectively. This is because fine silica sand as the aggregate in SHGC specimens had a restraining effect on drying shrinkage due to the excellent stability in shape, and thus controlled the volume stability of samples as the skeleton in SHGC specimens [42].

\subsection{Compressive strength}

Fig. 5 shows the typical failure mode of SHGC specimen at $28 \mathrm{~d}$ along with the loading direction. The red line indicates the cut plane perpendicular to the loading direction after uniaxial compression test, which will be explained in detail below. When the peak load was reached, all SHGC specimens remained the original cubic shape while a series of microcracks can be observed on the surface of specimens. These findings are consistent with those reported in other studies $[12,22]$. Noticeable vertical macrocrack parallel to the loading direction appeared on the specimen. The propagation of microcracks and sliding of matrix were limited by fibres incorporated in SHGC specimens due to the bridging effect, which also constrained the lateral expansion of specimens subjected to compressive load.

Fig. 6 displays the compressive strength of SHGC specimens with various sand content ranging from $0 \%$ to $40 \%$ by weight. The inclusion of fine silica sand resulted in a drop of the compressive strength of SHGC specimens. At 1 d, SHGC paste without sand (SHGC0) had a compressive strength of $18.73 \mathrm{MPa}$. The increase of sand content up to $40 \mathrm{wt} \%$ (SHGC4) gradually reduced the compressive strength of SHGC specimens by $35.7 \%$. Compared to SHGC0, when the sand content 
was increased by $10 \mathrm{wt} \%$ (SHGC1) and $20 \mathrm{wt} \%$ (SHGC2), there existed a negligible reduction (1.2\% and $5.8 \%$, respectively) in compressive strength of SHGC specimens. When the sand content was increased by $30 \mathrm{wt} \%$ (SHGC3) and $40 \mathrm{wt} \%$ (SHGC4), the reduction trend was more pronounced, showing a decrease in compressive strength by $22.0 \%$ and $35.7 \%$, respectively. Compared to $1 \mathrm{~d}$, the compressive strength of SHGC paste without sand (SHGC0) had an increase of $77.7 \%$ at $7 \mathrm{~d}$, reaching the value of 33.28 MPa. At $7 \mathrm{~d}$, compared to SHGC0, the addition of $10 \mathrm{wt} \%$ sand led to a drop in compressive strength of SHGC specimens by $12.0 \%$, but the further increase of sand content by 20 wt\% (SHGC2), $30 \mathrm{wt} \%$ (SHGC3), and $40 \mathrm{wt} \%$ (SHGC4) marginally reduced the compressive strength of SHGC specimens by $17.5 \%, 16.3 \%$, and 19.5\%, respectively. At $28 \mathrm{~d}$, the compressive strength of SHGC0 was further developed to $42.89 \mathrm{MPa}$. Compared to SHGC0, the incorporation of $10 \mathrm{wt} \%$ sand (SHGC1) resulted in a slight increase in compressive strength by $7.8 \%$, but the further increase of sand content by $20 \mathrm{wt} \%$ (SHGC2), $30 \mathrm{wt} \%$ (SHGC3), and $40 \mathrm{wt} \%$ (SHGC4) effectively reduced the compressive strength of SHGC specimens by $27.6 \%, 20.4 \%$, and $33.4 \%$, respectively.

Generally, the inclusion of fine silica sand into the pure geopolymer paste could result in an increase in compressive strength of the paste (without fibre), but for SHGC specimens (with fibres), the incorporation of sand altered the trend, indicating the reduced compressive strength. This is because the additional sand in SHGC specimens could influence the distribution and orientation of fibres as well as the entrapped voids. The size and distribution of voids would influence the initiation of cracks, and the distribution and orientation of fibres would influence the propagation of cracks. The synergic effect of fibres and voids would affect the compressive strength of specimens.

To examine the distribution and orientation of fibres as well as the voids, the microstructure of SHGC was investigated. After the uniaxial compression test, SHGC specimens were cut perpendicular to the loading direction along with the red line indicated in Fig. 5. Images of crosssections captured using Dino-Lite digital microscope were converted into binary images to show features of fibres and voids (see Fig. 7). The blue area represents the matrix, while the white area stands for the fibres in SHGC specimens. As seen in Fig. 7a, fibres distributed randomly with concentrated and loosed areas shown in bottom-left and top-right of the figure, respectively. Compared to loosed fibre distribution, concentrated fibre distribution tended to better resist the crack propagation while the fibres were prone to corrugation, which could impair the effect of fibres. As shown in Fig. 6b, the fibre orientation was also random with both parallel and vertical directions to 
the cross-section displayed as the white lines and the white dots, respectively. Since fibres were randomly incorporated into SHGC specimens during the mixing process, the distribution and orientation of fibres were both random over the cross-section of SHGC specimens. The bridging effect was mainly functioned by fibres oriented vertically to the propagation direction of microcracks. The uneven fibre dispersion further resulted in an increase in the total porosity of SHGC specimens, as the air bubbles were difficult to escape during the vibration process and thus voids were formed $[4,43]$. The white area over the cross-section of SHGC specimen in Fig. 6c represents the voids. Most voids in SHGC specimens were tiny with a diameter of less than $10 \mu \mathrm{m}$ and few macro voids with a diameter of around $300 \mu \mathrm{m}$ exist. Furthermore, the weak interfacial transition zone also led to the reduction in compressive strength of SHGC specimens.

\subsection{Flexural behaviour}

Flexural behaviour of SHGC specimens is discussed below in terms of stress-deflection response, failure mode and cracking, flexural strength, and flexural toughness. Table 4 summarises the flexural properties of SHGC specimens at $28 \mathrm{~d}$ under four-point bending.

\subsubsection{Stress-deflection curves}

Fig. 8 shows the stress-deflection curves of all SHGC specimens with various sand content under four-point bending at 7 and 28d. All SHGC specimens exhibited deflection hardening behaviour, and the stress-deflection curves were marginally affected by the addition of fine silica sand. For each SHGC mixture, the stress-deflection curve mainly consisted of two stages. The first stage of the stress-deflection curve was a linear elastic line until the first crack initiated. In the second stage, the stress-deflection curve continued with a higher rate in deflection until reaching the ultimate load capacity of the specimen, and then the specimen failed. During the second stage, the stress-deflection curve contained serrated lines, which were corresponding to the initiation and propagation of microcracks. As the load increased, the number and width of cracks increased and can be more clearly observed. Table 4 presents the average ultimate flexural deflection of specimens, which was marginally influenced by the inclusion of fine silica sand. The SHGC paste without sand (SHGC0) had an average flexural deflection of $24.20 \mathrm{~mm}$. The SHGC specimens with sand content of $10 \mathrm{wt} \%$ (SHGC1) and $30 \mathrm{wt} \%$ (SHGC3) had a slightly larger average flexural deflection of $27.36 \mathrm{~mm}$ and $26.87 \mathrm{~mm}$, respectively, but the SHGC specimens with sand content of $20 \mathrm{wt} \%$ (SHGC1) and $40 \mathrm{wt} \%$ (SHGC3) had a slightly smaller average flexural deflection of $24.80 \mathrm{~mm}$ and $22.74 \mathrm{~mm}$, respectively. 
Similar as the compressive strength, the influence of sand content on the flexural properties of SHGC specimens can be attributed to the random distribution and orientation of fibres and the formed voids.

Among all mixtures, SHGC2 with $20 \%$ sand displayed the optimum deflection hardening behaviour, as illustrated in Fig. 8c, which is used to explain the deflection hardening behaviour of SHGC at 7 and $28 \mathrm{~d}$. Compared to $7 \mathrm{~d}$, SHGC specimens presented higher first crack strength and ultimate flexural strength at $28 \mathrm{~d}$. At $7 \mathrm{~d}$, the first crack and ultimate flexural strengths of SHGC specimens were 2.90 MPa and 8.03 MPa, respectively. At $28 \mathrm{~d}$, the first crack and ultimate flexural strengths of SHGC specimens were 3.92 MPa and 8.97 MPa, respectively. This is because the matrix strength was still developing, and the fibre-matrix interfacial bond strength also increased with the geopolymerisation process as the curing age increased [44]. However, the increase in strength in turn caused the reduction in flexural deflection of SHGC specimens at $28 \mathrm{~d}$. For instance, the average flexural deflection of SHGC2 was $32.03 \mathrm{~mm}$ and $24.8 \mathrm{~mm}$ at $7 \mathrm{~d}$ and $28 \mathrm{~d}$, respectively. On the other hand, the slope of elastic region in the stress-deflection curves indicated the elastic modulus of SHGC specimens, which increased with the increase of curing age. At $7 \mathrm{~d}$, the slope had an average value of 3.46, which was increased to 4.46 at $28 \mathrm{~d}$, indicating that the SHGC specimens at $28 \mathrm{~d}$ became more brittle and therefore had a reduced flexural deflection capacity.

\subsubsection{Failure mode and cracking}

Figs. 9 shows the typical failure mode of SHGC specimens with a large deflection and multiple microcracks distributed over the tensile side of the specimen under four-point bending. During the bending test, the PVA fibres incorporated into the SHGC specimens can help them resist the tensile stress and release the strain energy due to toughening mechanisms, as explained in Section 3.5.4. Hence, the SHGC specimens behaved like a bendable slab rather than failed suddenly after the ultimate flexural strength was reached. The SHGC specimens failed until a clear macro-crack appeared due to insufficient bridging effect of fibres.

Cracks were captured immediately after the test stopped and before unloading, because many microcracks generated during the test completely closed after unloading, which made it difficult to detect cracks fully on the surface of unloaded specimens $[4,18]$. Crack number and average crack width of SHGC are listed in Table 4. Generally, the inclusion of fine silica sand resulted in a drop in the crack number but an increase in the average crack width of SHGC. Apart from SHGC paste without sand (SHGC0) that had an average crack number of 93 and average crack width of $68.2 \mu \mathrm{m}$, 
SHGC mortar with $10 \mathrm{wt} \%$ sand (SHGC1) had 132 cracks and an average crack width of $58.60 \mu \mathrm{m}$. Compared to SHGC1, the further incorporation of sand up to $40 \mathrm{wt} \%$ (SHGC4) led to a reduction in the crack number by $62.1 \%$ but an increase in the average crack width by $111.8 \%$. The excessive incorporation of sand would adversely affect the interaction between matrix and fibres in the SHGC specimens and further reduce the fibre bridging effect, as a result of which the fracture resistance and defection hardening behaviour were reduced [43]. Fig. 10 shows the effect of sand content on the crack number and crack width distribution of SHGC specimens. The microcracks of SHGC specimens had widths of less than $300 \mu \mathrm{m}$. Among them, in SHGC0, 58.4\% of microcracks distributed in the crack width range from $0 \mu \mathrm{m}$ to $45 \mu \mathrm{m}$. The addition of fine silica sand by $10 \mathrm{wt} \%$ (SHGC1) resulted in a slight increase in the number of microcracks that distributed in the width range of no more than $45 \mu \mathrm{m}$, which took $59.2 \%$ of the total crack number. However, when the sand content further increased by $20 \mathrm{wt} \%$ (SHGC2), $30 \mathrm{wt} \%$ (SHGC3), and $40 \mathrm{wt} \%$ (SHGC4), the percentage of microcracks with the width of no more than $45 \mu \mathrm{m}$ was reduced to $40.6 \%, 31.5 \%$, and $20.6 \%$ of the total crack number of SHGC specimens. With the increase of sand content, the SGHC specimens tended to have cracks with larger widths, which was associated with the brittleness of the geopolymer matrix.

\subsubsection{Flexural strength}

Fig. 11 shows the effect of sand content on the flexural strength of SHGC specimens at $7 \mathrm{~d}$ and $28 \mathrm{~d}$. At both $7 \mathrm{~d}$ and $28 \mathrm{~d}$, the flexural strength of SHGC specimens increased with the increase of sand up to $20 \mathrm{wt} \%$ (SHGC2), but further adding sand up to $40 \mathrm{wt} \%$ (SHGC4) led to a decrease in flexural strength of SHGC specimens. At $7 \mathrm{~d}$, SHGC paste without sand (SHGC0) had a flexural strength of 4.04 MPa. The increase of sand content up to $20 \mathrm{wt} \%$ (SHGC2) significantly increased the flexural strength of SHGC specimens by $99.0 \%$ compared to SHGC0, but the further increase of sand content decreased the flexural strength of SHGC specimens by $20.1 \%$ compared to SHGC2. At $28 \mathrm{~d}$, SHGC paste (SHGC0) had the lowest flexural strength of 6.48 MPa. Compared to SHGC0, the flexural strength was enhanced by $38.4 \%$ due to the incorporation of sand up to $20 \mathrm{wt} \%$ (SHGC2). However, SHGC specimens containing $30 \mathrm{wt} \%$ (SHGC3) and $40 \mathrm{wt} \%$ (SHGC4) sand indicated a reduction in flexural strength by $1.3 \%$ and $15.8 \%$, respectively, compared to SHGC2, which can be ascribed to the fibre corrugation caused by the interaction between matrix and fibre [43]. Overall, the flexural strength of SHGC specimen increased over time with geopolymerisation during the curing process. 
The increase of flexural strength resulted from the development of matrix strength and the bond strength between fibre and matrix. Moreover, PVA fibre is hydrophilic and the chemical bond between PVA fibre and geopolymer matrix can be developed during the curing process, which would also contribute to the development of flexural strength of SHGC. This may be the main reason why the number of microcracks became less with the increase of curing age.

\subsubsection{Flexural toughness}

Fig. 12 shows the influence of fine silica sand on the flexural toughness of SHGC specimens at $7 \mathrm{~d}$ and 28 d. At 7 d, the SHGC paste without sand (SHGC0) had a flexural toughness of $0.29 \mathrm{~J}$, which was increased by $171.9 \%$ with the increase of sand content up to $40 \mathrm{wt} \%$. However, at $28 \mathrm{~d}$, the influence of sand content on the flexural toughness of SHGC specimens was different. SHGC0 (0 wt $\%$ sand) had a flexural toughness of $0.48 \mathrm{~J}$. SHGC1 and SHGC2 containing $10 \mathrm{wt} \%$ and $20 \mathrm{wt} \%$ sand showed a $44.1 \%$ and $94.0 \%$ respectively higher flexural toughness compared to SHGC0. Unlike $7 \mathrm{~d}$, SHGC3 and SHGC4 containing $30 \mathrm{wt} \%$ and $40 \mathrm{wt} \%$ sand had a $6.8 \%$ and $10.8 \%$ respectively lower than SHGC2. As discussed in Sections 3.5.1 and 3.5.3 on the stress-deflection curves and flexural strength of SHGC specimens, the improvement of flexural toughness of SHGC specimens can be attributed to the increase of first-crack flexural strength, which was induced by the increased fracture toughness of the matrix due to the added sand and the developed strength of the matrix. However, the further addition of sand would result in the reduction in flexural strength due to the weakened interfacial transition zone between fibre and matrix.

Fig. 13a-d demonstrate the toughening mechanisms of SHGC, including fibre rupture, fibre pullout, and fibre bridging. Crack deflection and branching can also be observed in samples (see Fig. 13e-f), which can be attributed to fibre corrugation. Primarily, the development of deflection hardening behaviour of SHGC specimens can be ascribed to fibre bridging effect that limited the crack propagation within SHGC specimens under four-point bending. Once the crack initiated, the flexural stress was transferred to other parts of the specimens due to fibre bridging effect and prevent the sudden failure at the crack region. When the fibre at the crack region cannot resist the flexural stress, fibre rupture occurred, while fibre pull-out occurred when the flexural stress exceeded the bond strength between fibre and matrix. The increase of fine silica sand content resulted in fibre corrugation and crack branching, which adversely influenced the deflection hardening behaviour of SHGC specimens in terms of both flexural strength and flexural toughness [45-49]. 


\section{Conclusions}

This paper experimentally investigated the engineering properties of fly ash-slag based SHGC specimens cured at ambient temperature considering various fine silica sand content $(0 \%, 10 \%, 20 \%$, $30 \%$, and $40 \%$ by weight of the geopolymer binder). Fresh and hardened properties of SHGC specimens including flowability, setting time, drying shrinkage, compressive strength and flexural strength were investigated. Deflection hardening behaviour of SHGC specimens in terms of stressdeflection response, failure mode and cracking, and flexural toughness was explored. Based on the results in this study, the main conclusions can be drawn as follows:

- The incorporation of sand up to $40 \mathrm{wt} \%$ resulted in a reduction in workability of SHGC specimens for around $45 \%$ with the flow ranging from $68.3 \%$ to $37.3 \%$. The increase of sand content up to $40 \mathrm{wt} \%$ marginally reduced the initial and final setting time of SHGC specimens by approximately $20 \%$.

- The drying shrinkage of SHGC specimens was significantly decreased with the increase of sand content because of the restraining effect. The addition of $40 \mathrm{wt} \%$ sand reduced the drying shrinkage of SHGC specimens by $56.1 \%$ compared to SHGC paste.

- The compressive strength of SHGC was decreased with the increase of sand content. The incorporation of sand up to $40 \mathrm{wt} \%$ resulted in a decrease in compressive strength of SHGC specimens by $35.7 \%, 19.5 \%$, and $33.4 \%$, at $1 \mathrm{~d}, 7 \mathrm{~d}$, and $28 \mathrm{~d}$, respectively. Under uniaxial compression, all SHGC specimens preserved almost the cubic shape at failure because of the fibre bridging effect.

- All SHGC specimens exhibited deflection hardening behaviour with large deflection and multiple microcracks distributed over the tensile side of the specimens under four-point bending. The SHGC specimens containing $10 \mathrm{wt} \%$ sand presented the largest value in crack number but the smallest value in average crack width, i.e. 132 microcracks and $58.6 \mu \mathrm{m}$, respectively. The increase of sand content resulted in the increased number of microcracks that had larger crack width. SHGC specimens with a longer curing age tended to have a higher flexural but lower flexural deflection.

- The flexural strength and flexural toughness of SHGC specimens were increased with the increase of curing age. At $28 \mathrm{~d}$, compared to SHGC0, adding sand up to $20 \mathrm{wt} \%$ resulted in the increase in flexural strength and flexural toughness by $38.4 \%$ and $94.0 \%$, respectively, but the 
further increase of sand content reduced the flexural strength and flexural toughness. The changes in flexural strength and toughness were governed by fibre toughening mechanisms, including fibre rupture, fibre pull-out, and fibre bridging.

- The incorporation of $20 \mathrm{wt} \%$ fine silica sand can be suggested as the optimal mixture of fly ashslag based SHGC considering the engineering properties.

\section{Acknowledgements}

The authors gratefully acknowledge the financial support of the Engineering and Physical Sciences Research Council (EPSRC) via grant EP/R041504/1 "Development of a novel self-healing composite for sustainable and resilient concrete infrastructure" as well as the Royal Society under Award No. IEC\NSFC $\backslash 191417$.

\section{References}

[1] Li VC. On engineered cementitious composites (ECC) - A review of the material and its applications. J Adv Concr Technol 2003;1(3):215-230.

[2] Bosoaga A, Masek O, Oakey JE. $\mathrm{CO}_{2}$ capture technologies for cement industry. Energy Procedia 2009; 1(1):133-140.

[3] Ahmed SFU, Ronnie Z. Ductile behavior of polyethylene fibre reinforced geopolymer composite. Eng Technol Int Conf 2016 (Etic 2016) 2017;97:01047.

[4] Nematollahi B, Sanjayan J, Shaikh FUA. Matrix design of strain hardening fiber reinforced engineered geopolymer composite. Compos Part B-Eng 2016;89:253-265.

[5] Ohno M, Li VC. A feasibility study of strain hardening fiber reinforced fly ash-based geopolymer composites. Constr Build Mater 2014;57:163-168.

[6] Ohno M, Li VC. An integrated design method of Engineered Geopolymer Composite. Cement Concrete Comp 2018;88:73-85.

[7] Choi JI, Lee BY, Ranade R, Li VC, Lee Y. Ultra-high-ductile behavior of a polyethylene fiberreinforced alkali-activated slag-based composite. Cement Concrete Comp 2016;70:153-158.

[8] Trindade ACC, Borges PHR, Silva FDA. Mechanical behavior of strain-hardening geopolymer composites reinforced with natural and PVA fibers. Mater Today-Proc 2019;8(3):753-759.

[9] Nematollahi B, Sanjayan J, Qiu J, Yang EH. Micromechanics-based investigation of a sustainable ambient temperature cured one-part strain hardening geopolymer composite. Constr Build Mater 2017;131:552-563. 
[10] Nematollahi B, Sanjayan J, Qiu J, Yang EH. High ductile behavior of a polyethylene fiberreinforced one-part geopolymer composite: A micromechanics-based investigation. Arch Civ Mech Eng 2017;17(3):555-563.

[11] Ling Y, Wang K, Li W, Shi G, Lu P. Effect of slag on the mechanical properties and bond strength of fly ash-based engineered geopolymer composites. Compos Part B-Eng 2019;164:747-757.

[12] Alrefaei Y, Dai JG. Tensile behavior and microstructure of hybrid fiber ambient cured one-part engineered geopolymer composites. Constr Build Mater 2018;184:419-431.

[13] Al-Majidi MH, Lampropoulos A, Cundy AB. Tensile properties of a novel fibre reinforced geopolymer composite with enhanced strain hardening characteristics. Compos Struct 2017;168:402-427.

[14] Batista RP, Trindade ACC, Borges PHR, Silva FDA. Silica fume as precursor in the development of sustainable and high-performance MK-based alkali-activated materials reinforced with short PVA fibers. Front Mater 2019;00077.

[15] Nematollahi B, Qiu J, Yang EH, Sanjayan J. Micromechanics constitutive modelling and optimization of strain hardening geopolymer composite. Ceram Int 2017;43(8):5999-6007.

[16] Zahid M, Shafiq N, Isa MH, Gil L. Statistical modeling and mix design optimization of fly ash based engineered geopolymer composite using response surface methodology. J Clean Prod 2018; 194:483-498.

[17] Nematollahi B, Sanjayan J, Shaikh FUA. Comparative deflection hardening behavior of short fiber reinforced geopolymer composites. Constr Build Mater 2014;70:54-64.

[18] Nematollahi B, Sanjayan J, Shaikh FUA. Tensile strain hardening behavior of PVA fiberreinforced engineered geopolymer composite. J Mater Civil Eng 2015;27(10):04015001.

[19] Nematollahi B, Qiu J, Yang EH, Sanjayan J. Microscale investigation of fiber-matrix interface properties of strain-hardening geopolymer composite. Ceram Int 2017;43(17):15616-15625.

[20] Shaikh FUA. Deflection hardening behaviour of short fibre reinforced fly ash based geopolymer composites. Mater Design 2013;50:674-682.

[21] Nematollahi B, Ranade R, Sanjayan J, Ramakrishnan S. Thermal and mechanical properties of sustainable lightweight strain hardening geopolymer composites. Arch Civ Mech Eng 2017;17(1):55-64.

[22] Lee BY, Cho CG, Lim HJ, Song JK, Yang KH, Li VC. Strain hardening fiber reinforced alkali- 
activated mortar - A feasibility study. Constr Build Mater 2012;37:15-20.

[23] Nguyen H, Carvelli V, Adesanya E, Kinnunen P, Illikainen M. High performance cementitious composite from alkali-activated ladle slag reinforced with polypropylene fibers. Cement Concrete Comp 2018;90:150-160.

[24] Nguyen H, Staudacher M, Kinnunen P, Carvelli V, Illikainen M. Multi-fiber reinforced ettringite-based composites from industrial side streams. J Clean Prod 2019;211:1065-1077.

[25] Alshaaer M, Mallouh SA, Al-Kafawein J, Al-Faiyz Y, Fahmy T, Kallel A, Rocha F. Fabrication, microstructural and mechanical characterization of Luffa Cylindrical Fibre - Reinforced geopolymer composite. Appl Clay Sci 2017;143:125-133.

[26] Shaikh FUA, Fairchild A, Zammar R. Comparative strain and deflection hardening behaviour of polyethylene fibre reinforced ambient air and heat cured geopolymer composites. Constr Build Mater 2018;163:890-900.

[27] Nematollahi B, Sanjayan J. Effect of different superplasticizers and activator combinations on workability and strength of fly ash based geopolymer. Mater Design 2014;57:667-672.

[28] Ranjbar N, Zhang M. Fiber-reinforced geopolymer composites: A review. Cement Concrete Comp 2020;107:103498.

[29] Li V, Wu C, Wang SX, Ogawa A, Saito T. Interface tailoring for strain-hardening polyvinyl alcohol-engineered cementitious composite (PVA-ECC). ACI Mater J 2002;99:463-472.

[30] Fang G, Ho WK, Tu W, Zhang M. Workability and mechanical properties of alkali-activated fly ash-slag concrete cured at ambient temperature. Constr Build Mater 2018;172:476-487.

[31] Fang G, Bahrami H, Zhang M. Mechanisms of autogenous shrinkage of alkali-activated fly ashslag pastes cured at ambient temperature within 24 h. Constr Build Mater 2018;171:377-387.

[32] Tu W, Zhu Y, Fang G, Wang X, Zhang M. Internal curing of alkali-activated fly ash-slag pastes using superabsorbent polymer. Cement Concrete Res 2019;116:179-190.

[33] Wang A, Zhang C, Sun W. Fly ash effects: I. The morphological effect of fly ash. Cement Concrete Res 2003;33(12):2023-2029.

[34] Huseien GF, Ismail M, Khalid NHA, Hussin MW, Mirza J. Compressive strength and microstructure of assorted wastes incorporated geopolymer mortars: Effect of solution molarity. Alex Eng J 2018;57(4):3375-3386.

[35] Khan MI, Fares G, Mourad S, Abbass W. Optimized Fresh and Hardened Properties of Strain- 
Hardening Cementitious Composites: Effect of Sand Size and Workability. J Mater Civil Eng 2016;28(12):04016152.

[36] Siyal AA, Azizli KA, Man Z, Ullah H. Effects of parameters on the setting time of fly ash based geopolymers using Taguchi method. Procedia Eng 2016;148:302-307.

[37] Temuujin J, Riessen AV, MacKenzie KJD. Preparation and characterisation of fly ash based geopolymer mortars. Constr Build Mater 2010;24(10):1906-1910.

[38] Aldabsheh I, Garcia-Valles M, MartinezS. Interaction of micro/nano-metric size of Jordanian aluminosilicate raw materials with high pH solution. Mater 2018;229:57-59.

[39] Kuenzel C, Vandeperre LJ, Donatello S, Boccaccini AR, Cheeseman C. Ambient temperature drying shrinkage and cracking in metakaolin-based geopolymers. J Am Ceram Soc 2012;95(10):3270-3277.

[40] Scherer GW. Theory of drying. J Am Ceram Soc 1990;73(1):3-14.

[41] Yang T, Zhu H, Zhang Z. Influence of fly ash on the pore structure and shrinkage characteristics of metakaolin-based geopolymer pastes and mortars. Constr Build Mater 2017;153:284-293.

[42] Mastali M, Kinnunen P, Dalvand A, Firouz RM, Illikainen M. Drying shrinkage in alkaliactivated binders - A critical review. Constr Build Mater 2018;190:533-550.

[43] Akkaya Y, Peled A, Picka JD, Shah SP. Effect of sand addition on properties of fiber-reinforced cement composites. ACI Struct J 2000;97(3):393-400.

[44] Altwair NM, Johari MAM, Hashim SFS. Flexural performance of green engineered cementitious composites containing high volume of palm oil fuel ash. Constr Build Mater 2012;37:518-525.

[45] Noushini A, Hastings M, Castel A, Aslani F. Mechanical and flexural performance of synthetic fibre reinforced geopolymer concrete. Constr Build Mater 2018;186:454-475.

[46] Ranjbar N, Talebian S, Mehrali M, Kuenzel C, Metselaar HSC, Jumaat MZ. Mechanisms of interfacial bond in steel and polypropylene fiber reinforced geopolymer composites. Compos Sci Technol 2016;122:73-81.

[47] Bhutta A, Borges PHR, Zanotti C, Farooq M, Banthia N. Flexural behavior of geopolymer composites reinforced with steel and polypropylene macro fibers. Cement Concrete Comp 2017;80:31-40.

[48] Xu F, Deng X, Peng C, Zhu J, Chen J. Mix design and flexural toughness of PVA fiber reinforced 
fly ash-geopolymer composites. Constr Build Mater 2017;150:179-189.

[49] Wang Y, Chan CL, Leong SH, Zhang M. Engineering properties of strain hardening geopolymer composites with hybrid polyvinyl alcohol and recycled steel fibre. Constr Build Mater 2020. under revision. 
Table 1. Literature review of strain hardening geopolymer composites.

\begin{tabular}{|c|c|c|c|c|}
\hline Ref & Binder & Fibre & Specimen & Major findings \\
\hline $\begin{array}{l}\text { Nematollahi } \\
\text { et al. [15] }\end{array}$ & FA & PVA & Paste & $\begin{array}{l}\text { - In FA-SHGCs, critical fibre content required to display saturated pseudo-strain-hardening } \\
\text { behaviour is primarily governed by energy-based criterion. } \\
\text { - Critical fibre content could be reduced by the fibre surface oil coating, the increase of } \\
\text { fibre length, and the reduction of matrix fracture toughness. }\end{array}$ \\
\hline $\begin{array}{l}\text { Zahid et al. } \\
{[16]}\end{array}$ & FA & PVA & Paste & - Simulation results agreed well with experimental data (less than 5\% difference). \\
\hline $\begin{array}{l}\text { Nematollahi } \\
\text { et al. [17] }\end{array}$ & FA & PVA & Paste & $\begin{array}{l}\text { - All SHGC exhibited deflection hardening behaviour accompanied by multiple micro- } \\
\text { cracks in bending, regardless of activator type. } \\
\text { - SHGC-Na-1 displayed the superior deflection capacity, matrix fracture properties, } \\
\text { compressive and flexural strengths, ductility and toughness. }\end{array}$ \\
\hline $\begin{array}{l}\text { Nematollahi } \\
\text { et al. [18] }\end{array}$ & FA & PVA & Paste & $\begin{array}{l}\left.\text { - Na-based activator combination ( } 8 \mathrm{M} \mathrm{NaOH} \text { solution, } \mathrm{SiO}_{2} / \mathrm{Na}_{2} \mathrm{O} \text { ratio of } 2.0\right) \text { was } \\
\text { superior in terms of higher compressive strength, matrix fracture properties and uniaxial } \\
\text { tensile behaviour as well as lower cost. }\end{array}$ \\
\hline $\begin{array}{l}\text { Nematollahi } \\
\text { et al. [19] }\end{array}$ & FA & PVA & Paste & $\begin{array}{l}\text { - Regardless of activator type and w/b ratio, the chemical bond and slip hardening } \\
\text { coefficient of oil-coated PVA fibre were lower than virgin fibre. } \\
\text { - The frictional bond between fibre and matrix depended on activator type: in Na-based } \\
\text { activator, oil-coated PVA fibre outperforms virgin fibre (reverse in K-based activator). } \\
\text { - Reducing w/b ratio increased chemical bond but decreased the frictional bond of PVA } \\
\text { fibre with Na-based matrix. }\end{array}$ \\
\hline $\begin{array}{l}\text { Ahmed and } \\
\text { Ronnie [3] }\end{array}$ & FA & $\mathrm{PE}$ & Paste & $\begin{array}{l}\text { - Optimum fibre volume content: } 1 \% \text { (among } 0.5 \%, 1 \%, 1.5 \% \text {, and } 2 \% \text { ) for strain and } \\
\text { deflection hardening behaviour in uniaxial tension and three-point bending tests. } \\
\text { - Compressive strength of the composites decreased with the increase of volume content of } \\
\text { PE fibre. } \\
\text { - Alkaline geopolymer matrix had no significant damage to PE fibre. }\end{array}$ \\
\hline
\end{tabular}


Shaikh [20] FA Steel; $\quad$ Mortar

PVA;

Steel \&

PVA

$\begin{array}{llll}\text { Nematollahi } & \text { FA } & \text { PVA } & \text { Mortar (light- } \\ \text { et al. [21] } & & & \text { weight }\end{array}$

aggregates)

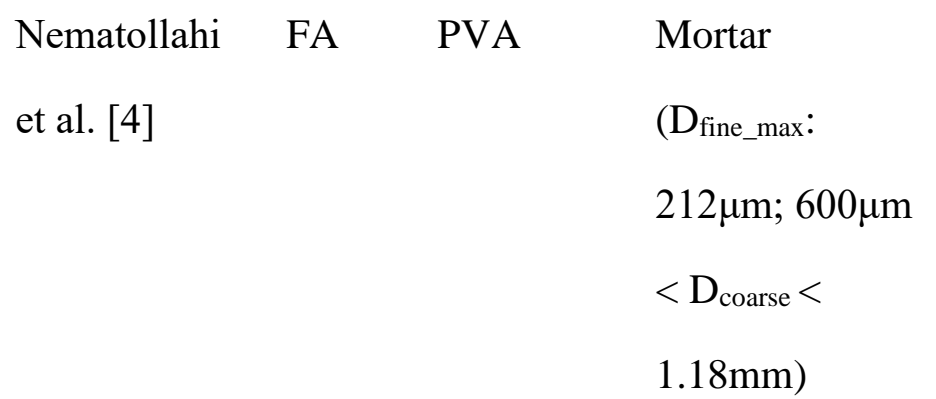

Ohno and Li FA PVA Mortar

Ohno and Li FA PVA Mortar
- The deflection hardening behaviour with multiple cracks was derived from FA-based geopolymer.

- If the sand size and sand content were given, both cement and geopolymer based composites, regardless of fibre types and combination, showed comparable deflection hardening behaviour, ultimate flexural strength and deflection at peak load.

- Geopolymer matrix did not degrade PVA and steel fibres.

- All SHGC developed by lightweight aggregates meet the criteria (i.e. density and compressive strength) for structural lightweight concrete.

- Compressive and tensile strength: SHGC (lightweight aggregates) < SHGC (normal weight micro-silica sand).

- Tensile ductility: SHGC (lightweight aggregates) SHGC (normal weight micro-silica sand).

- Thermal conductivity: SHGC (lightweight aggregates) < SHGC (normal weight microsilica sand).

- Lowering water to geopolymer solids ratio and the addition of sand enhanced the elastic modulus of the geopolymer matrix and composite in all cases.

- Excessive use of fine sand and the use of coarse sand adversely affected the strain hardening behaviour of SHGC due to the increase of the matrix fracture toughness and the first crack strength of the composite.

- Desirable tensile ductility of SHGC could be only maintained by geopolymer matrices with suitable fracture toughness as defined by the micromechanics design model.

- SHGC exhibited tensile strain hardening behaviour with very high ductility of over $4 \%$.

- Temperature curing methods could improve compressive strength, tensile strength and tensile ductility.

- Maximum and average crack widths were $117 \mu \mathrm{m}$ and $45 \mu \mathrm{m}$ (even at strain level of $4.5 \%$ ).

- The systematic design process could optimise SHGC to achieve improved compressive strength (43.1\%), high tensile ductility (4.7\%), less embodied energy (11\% less than $\mathrm{SHCC}$ ), and $\mathrm{CO}_{2}$ equivalent emissions (55\% less than SHCC). 
Choi et al. [7] GGBS PE Paste

Lee et al. GGBS PVA Mortar

[22]

\begin{tabular}{|c|c|c|c|}
\hline Nguyen et al. & Ladle & PP & Mortar ( $D_{50}$ : \\
\hline [23] & slag & & $1450 \mu \mathrm{m})$ \\
\hline
\end{tabular}

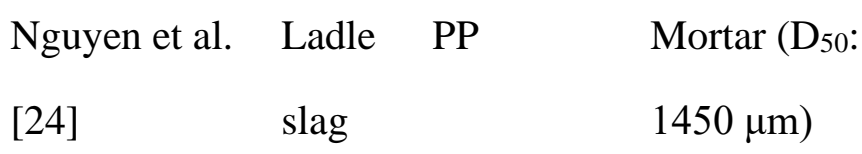

\begin{tabular}{llll} 
Alshaaer et & MK & Luffa & Paste \\
al. [25] & \multicolumn{3}{c}{ cylindrical }
\end{tabular}

fibre
- The average tensile strength to compressive strength ratio of the composites was $19.8 \%$, nearly double that of normal concrete.

- Average crack width was $101 \mu \mathrm{m}$.

- The composite could reach tensile strain capacity and tensile strength of up to $7.5 \%$ and 13.06 MPa, respectively.

- Achieved high tensile ductility of $4.7 \%$, compared with $0.02 \%$ for the mortar matrix alone.

- The composite could gain very high ductility with an appropriate fibrous reinforcement.

- PP fibre reinforced composite has higher flexural strength, fracture energy and fracture toughness compared to unreinforced material.

- Samples showed pseudo strain hardening behaviour with multi-cracking under uniaxial tension test.

- High mechanical performance of the PP-reinforced composite is obtained by local fibre bridging effect.

- All composites showed strain hardening behaviour with multi-cracks under tensile and flexural loading.

- The compressive strength of the composites is higher than the plain material.

- PP micro-fibre reinforced composites is the best mixture to balance the mechanical and economic aspects, based on a multi-criterion ranking method.

- The rough LCF has hydrophobicity and contributes to the strengthening of bonding between fibre and geopolymer matrix.

- The incorporation of the extracted constituents of luffa cylindrical fibre created two main morphological types of crystalline objects, which contributes to crack healing while improving tensile strength and toughness of the composite.

- The addition of LCF increased the compressive and flexural strength of the end geopolymeric products.

- Unlike the brittle matrix, geopolymer matrix reinforced with LCF exhibited strain hardening behaviour with elastic modulus of $72 \mathrm{MPa}$. 
Trindade et

al. [8]

$\mathrm{MK}$

Jute

$\operatorname{Mortar}\left(\mathrm{D}_{\max }\right.$ :

- All SHGC exhibited strain hardening behaviour with multiple cracking formations.

Sisal; $\quad 1.18 \mathrm{~mm}$

Curauá;

PVA

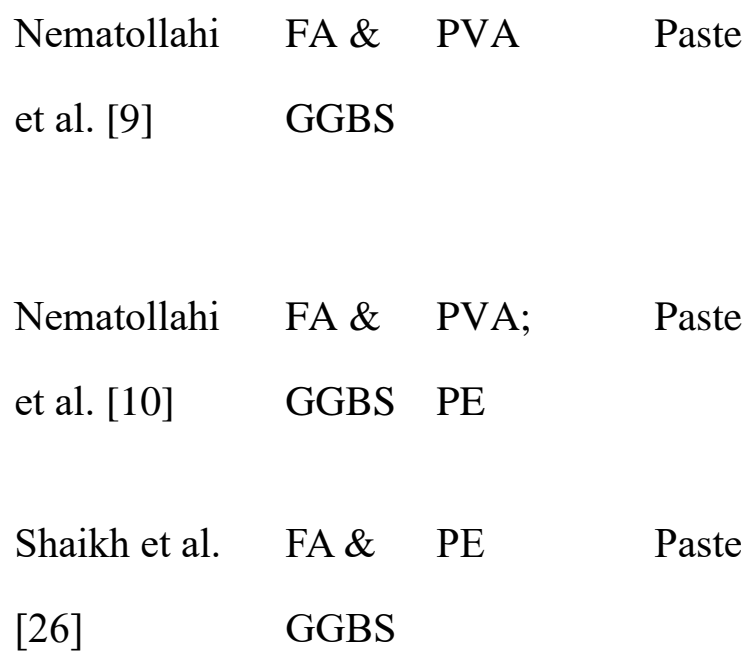

[26] GGBS

Ling et al. FA \& PVA Paste

[11] GGBS
- SHGC demonstrated strong strain hardening behaviour comparable to typical SHCC with high tensile strength (4.6 MPa) and very high tensile strain capacity (4.2\%).

- The developed ambient temperature cured one-part SHGC is a promising sustainable alternative to typical SHCC offering $76 \%$ fewer carbon emissions and 36\% less energy consumption.

- For one-part PE-SHGCs, the ambient temperature curing increased the compressive strength and tensile strengths, but reduced the tensile ductility.

- Compared to one-part PVA-SHGC, PE-SHGCs exhibited lower compressive and tensile strengths, but higher tensile ductility.

- Strain hardening and deflection hardening behaviour: SHGC (both ambient and heatcured) $>$ SHCC.

- Deflection and uniaxial tension capacity: ambient cured SHGC $>$ heat-cured SHGC.

- Compressive strength: SHGC (both ambient and heat-cured) $<$ SHCC.

- PE fibre volume fractions to achieve optimum tensile strain, deflection at peak load and maximum number of multiple cracks: 0.75-1.0\% (both SHGC and SHCC).

- Cement matrix and geopolymer gel adhered on PE fibres (possibly higher frictional bond of PE fibre): ambient cured SHGC $<$ heat-cured SHGC.

- All SHGC exhibited strain hardening behaviour under tension and flexure.

- Increasing slag content enhanced strength-related properties but reduced ductility-related properties of SHGC, mainly due to the improved density of SHGC matrix and bond between matrix and fibre. 


$\begin{array}{llll}\text { Alrefaei and } & \text { FA \& } & \text { Steel \& } & \text { Mortar }\left(D_{\max }:\right. \\ \text { Dai [12] } & \text { GGBS } & \text { PE } & 212 \mu \mathrm{m})\end{array}$

Al-Majidi et FA \& Steel; $\quad$ Mortar (silica

al. [13] GGBS Glass; sand)

\& SF PVA.

Batista et al. MK \& PVA Mortar $\left(D_{\max }\right.$ :

[14] SF $\quad 0.6 \mathrm{~mm}$

fineness

modulus 1.03)
- $20 \%$ GGBS replacement shows optimum strength-related properties (compressive, flexural, and bond strengths) but not for ductility-related properties (tensile strain capacity, maximum flexural deformation, ultimate slip, and toughness).

- GGBS-based SHGC and FA-GGBS based SHGC achieved comparable compressive strength, but the former exhibited a relatively better tensile response in strain hardening and multi-cracking behaviours.

- The matrix of GGBS-based SHGC was relatively denser and more compacted than FAGGBS based SHGC.

- For both GGBS-based and FA-GGBS based SHGC, additional sand reduced the strain hardening and multi-cracking behaviours but increased the compressive strength and fracture properties of the geopolymer matrices.

- Additional steel and PVA fibres increase the flexural and tensile strength of the ambient cured examined geopolymer matrix.

- Superior deflection capacity can be obtained by SHGC reinforced by $2 \%$ PVA fibre or $2 \%$ and $3 \%$ of $13 \mathrm{~mm}$ length steel fibre.

- The employment of SF could reduce the demand for sodium silicate in the alkaline activator, and further lower environmental impact (reduced $\mathrm{CO}_{2}$ emissions).

- Adjusting the formulations could improve flexion toughness in $170 \%$ with $30 \mathrm{wt} \%$ reduction of sodium silicate in the activator and improve deformation capability in tension. 
Table 2. Chemical compositions (wt $\%$ ) of FA and GGBS.

\begin{tabular}{lllllllllll}
\hline Oxide & $\mathrm{SiO}_{2}$ & $\mathrm{Al}_{2} \mathrm{O}_{3}$ & $\mathrm{CaO}$ & $\mathrm{MgO}$ & $\mathrm{K}_{2} \mathrm{O}$ & $\mathrm{Fe}_{2} \mathrm{O}_{3}$ & $\mathrm{TiO}_{2}$ & $\mathrm{Na}_{2} \mathrm{O}$ & $\mathrm{SO}_{3}$ & $\mathrm{LOI}$ \\
\hline FA & 49.80 & 25.08 & 4.65 & 1.67 & 3.30 & 11.67 & 1.24 & 0.66 & 1.35 & 0.58 \\
GGBS & 36.77 & 13.56 & 37.60 & 7.45 & 0.55 & 0.41 & 0.79 & 0.25 & 1.82 & 0.8 \\
\hline
\end{tabular}

Note: LOI (loss on ignition).

Table 3. Mix proportions of SHGC.

\begin{tabular}{lllllll}
\hline \multirow{2}{*}{ Mix no. } & \multicolumn{2}{l}{ Binder } & Activator/binder & SPs/binder & $\begin{array}{l}\text { Fine silica } \\
\text { sand/binder }\end{array}$ & $\begin{array}{l}\text { Fibre } \\
\text { (vol\%) }\end{array}$ \\
\cline { 2 - 5 } & FA & GGBS & & 0.01 & 0 & 2 \\
\hline SHGC0 & 0.8 & 0.2 & 0.4 & 0.01 & 0.1 & 2 \\
SHGC1 & 0.8 & 0.2 & 0.4 & 0.01 & 0.2 & 2 \\
SHGC2 & 0.8 & 0.2 & 0.4 & 0.01 & 0.3 & 2 \\
SHGC3 & 0.8 & 0.2 & 0.4 & 0.01 & 0.4 & 2 \\
SHGC4 & 0.8 & 0.2 & 0.4 & & & \\
\hline
\end{tabular}

Table 4. Flexural properties of SHGC specimens at $28 \mathrm{~d}$.

\begin{tabular}{llllll}
\hline Mix no. & $\begin{array}{l}\text { Average ultimate } \\
\text { flexural strength } \\
(\mathrm{MPa})\end{array}$ & $\begin{array}{l}\text { Average ultimate } \\
\text { flexural deflection } \\
(\mathrm{mm})\end{array}$ & $\begin{array}{l}\text { Flexural } \\
\text { toughness }(\mathrm{J})\end{array}$ & $\begin{array}{l}\text { Crack } \\
\text { number }\end{array}$ & $\begin{array}{l}\text { Average crack } \\
\text { width }(\mu \mathrm{m})\end{array}$ \\
\hline SHGC0 & 6.48 & 24.20 & 0.48 & 93 & 68.2 \\
SHGC1 & 8.64 & 27.36 & 0.69 & 132 & 58.6 \\
SHGC2 & 8.97 & 24.80 & 0.93 & 98 & 80.0 \\
SHGC3 & 8.85 & 26.87 & 0.87 & 89 & 91.9 \\
SHGC4 & 7.55 & 22.74 & 0.83 & 50 & 124.1 \\
\hline
\end{tabular}




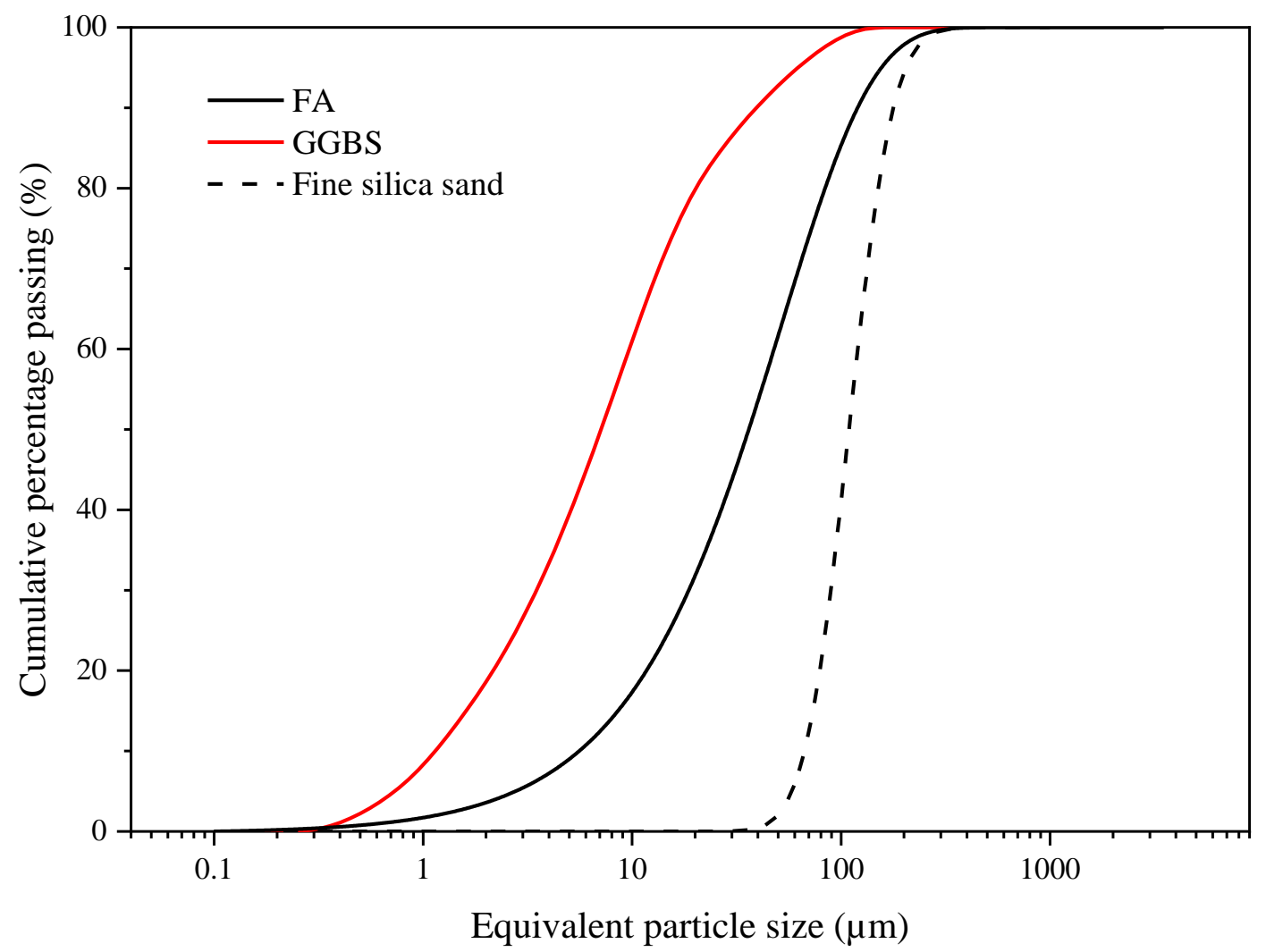

Fig. 1. Particle size distribution of FA, GGBS, and sand.

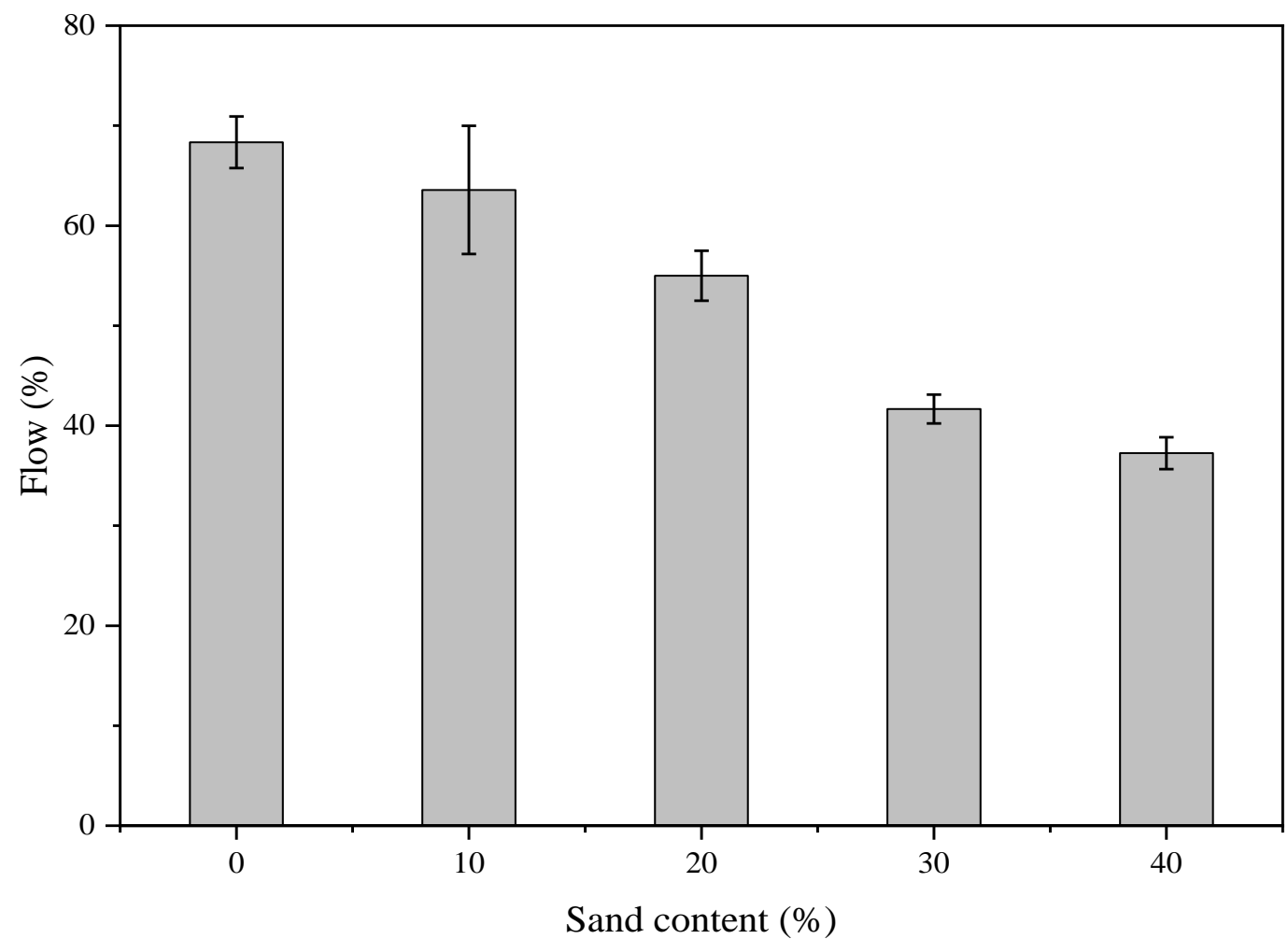

Fig. 2. Effect of sand content on flowability of fresh SHGC specimens. 


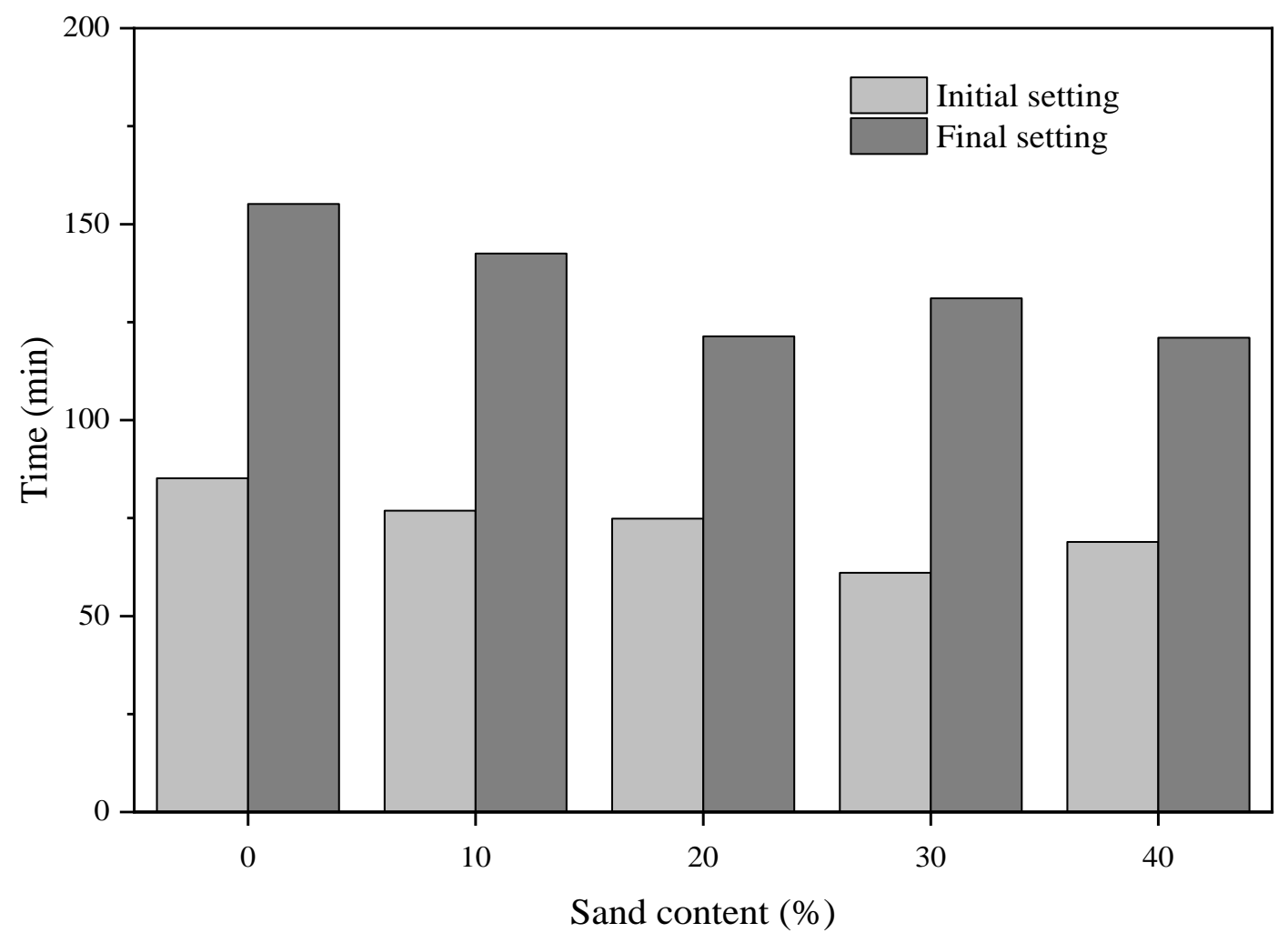

Fig. 3. Effect of sand content on setting time of SHGC specimens.

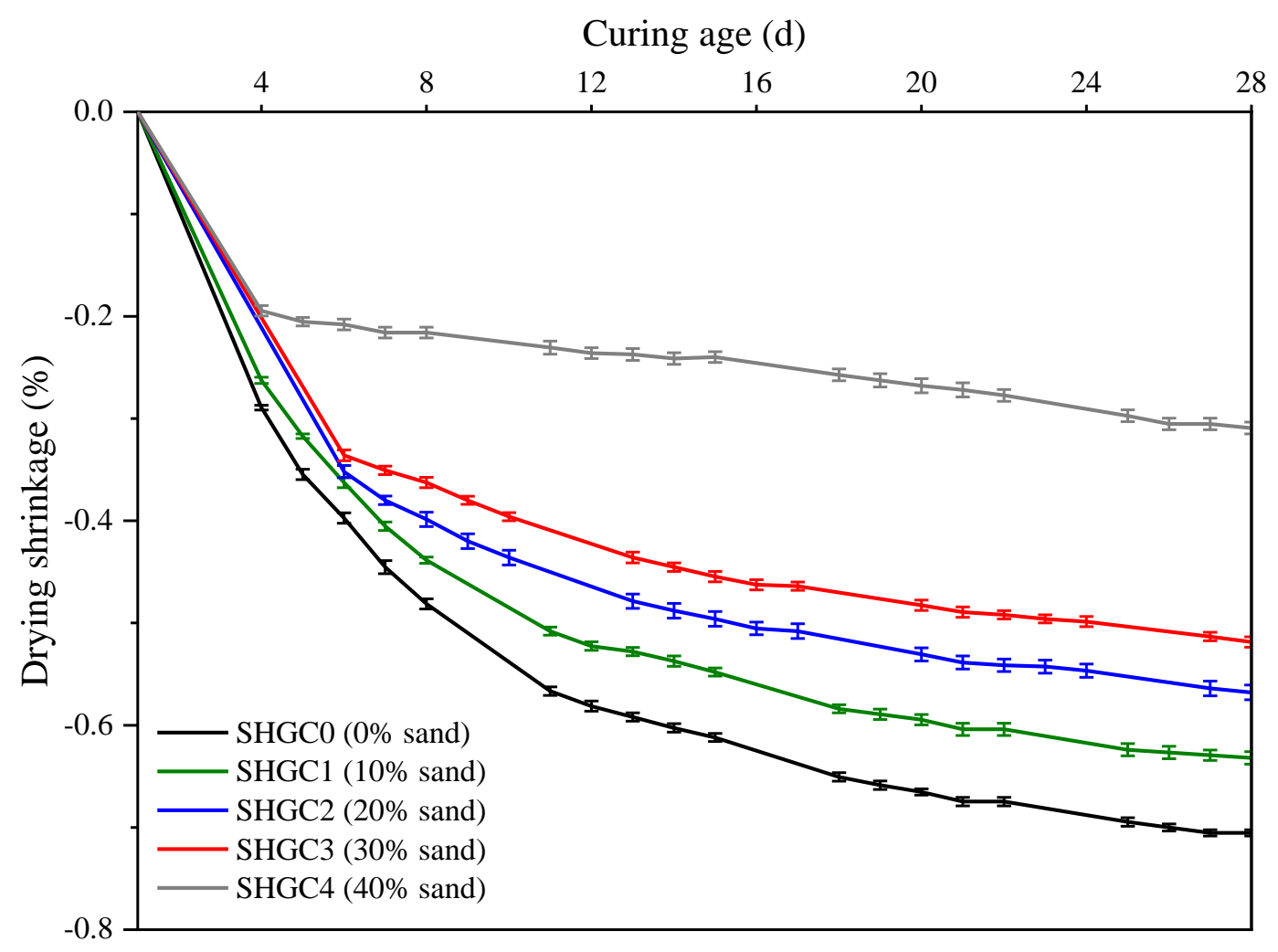

Fig. 4. Effect of sand content on drying shrinkage of SHGC specimens. 


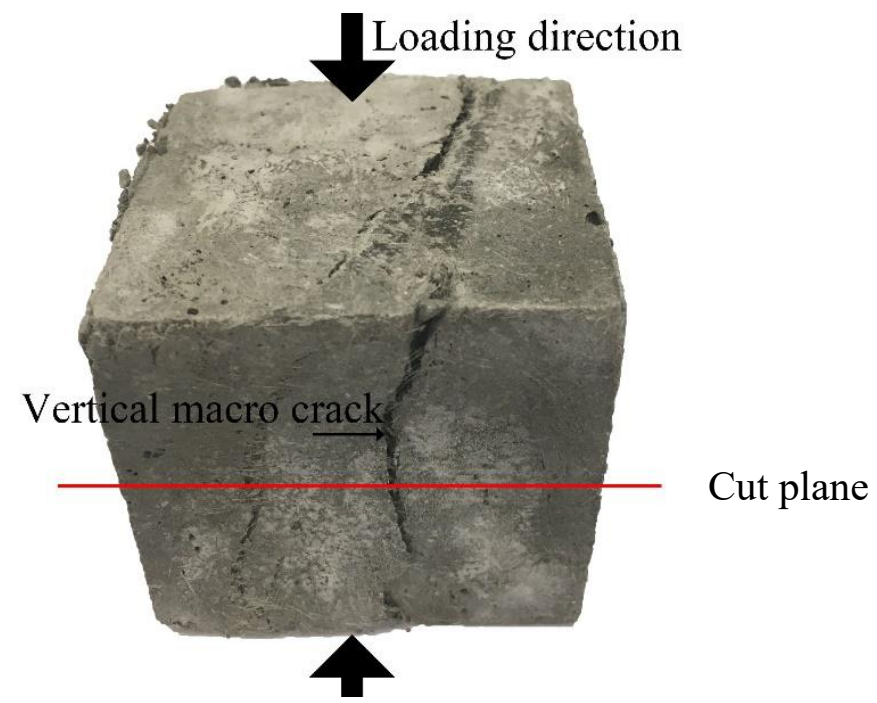

Fig. 5. Typical failure mode and loading direction of SHGC specimen at $28 \mathrm{~d}$.

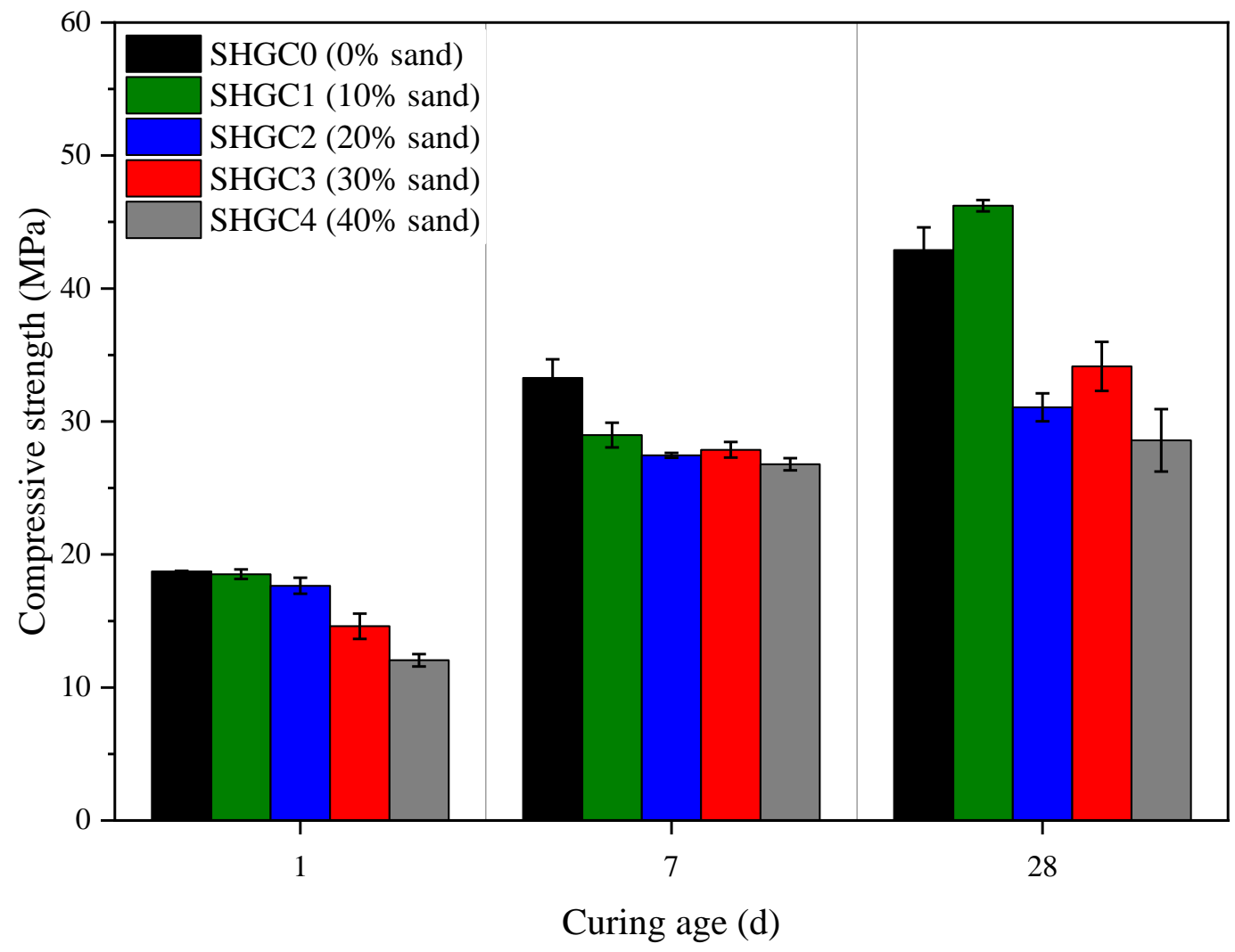

Fig. 6. Effect of sand content on compressive strength of SHGC specimens. 


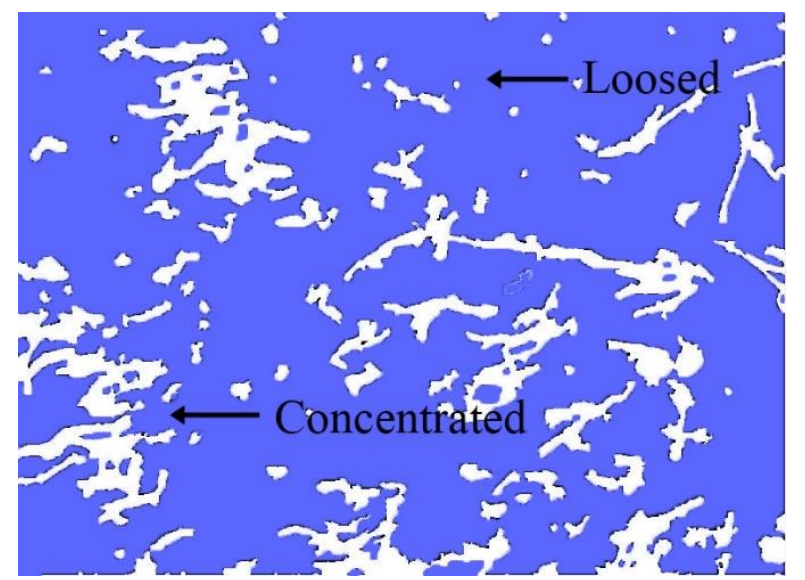

(a) Fibre distribution (SHGC4)

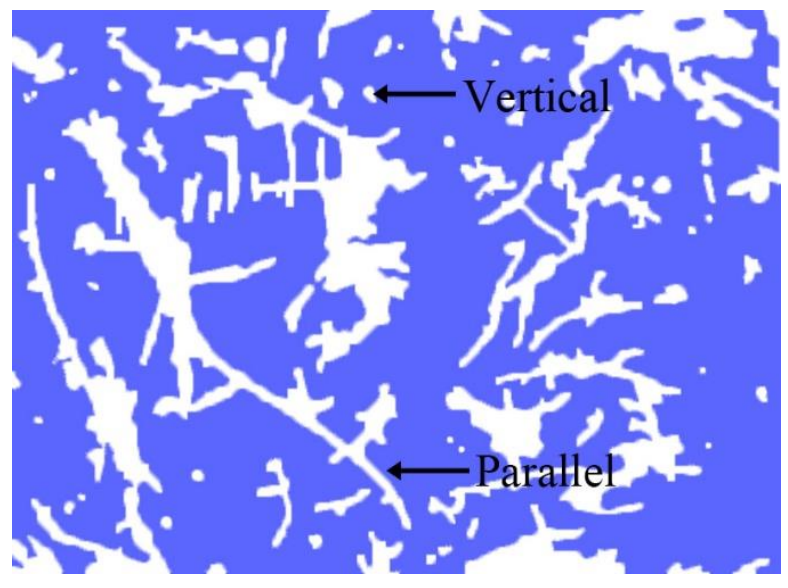

(b) Fibre orientation (SHGC4)

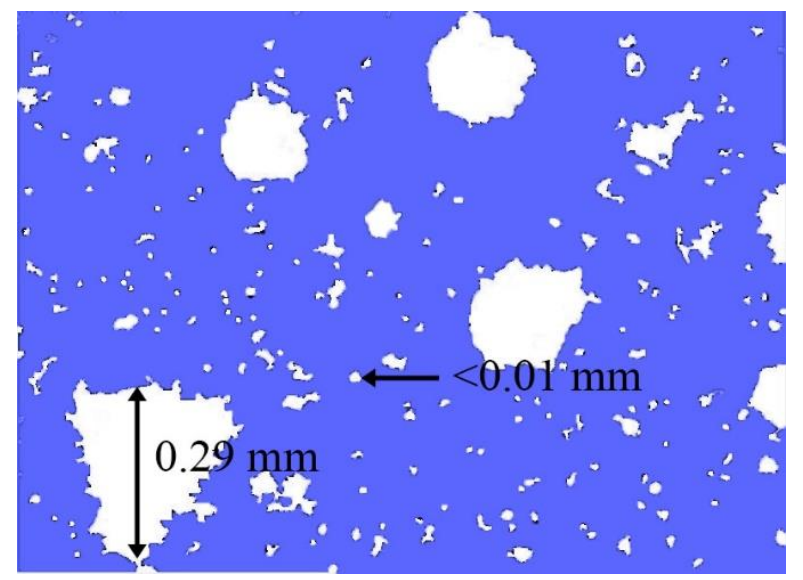

(c) Voids distribution and size (SHGC0)

Fig. 7. Typical features of fibres and voids over the cross-section of SHGC specimens. 

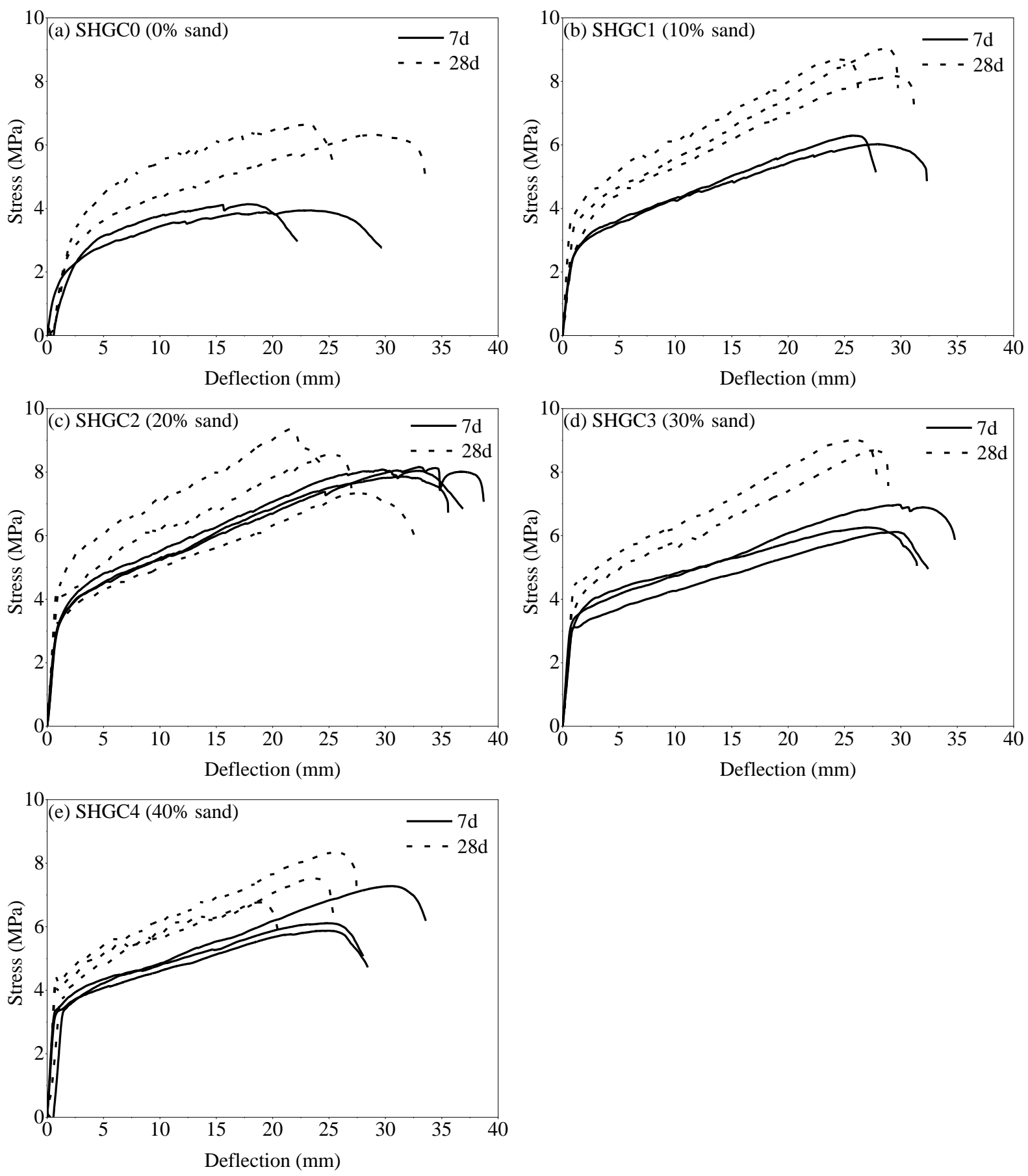

Fig. 8. Typical stress-deflection curves of SHGC specimens with various sand content at 7 and $28 \mathrm{~d}$. 


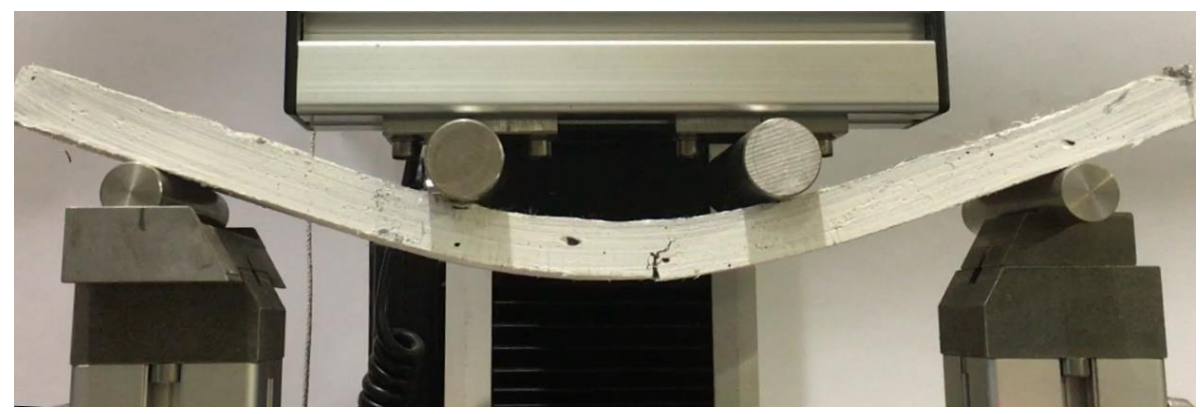

(a) Typical failure mode of the specimen.

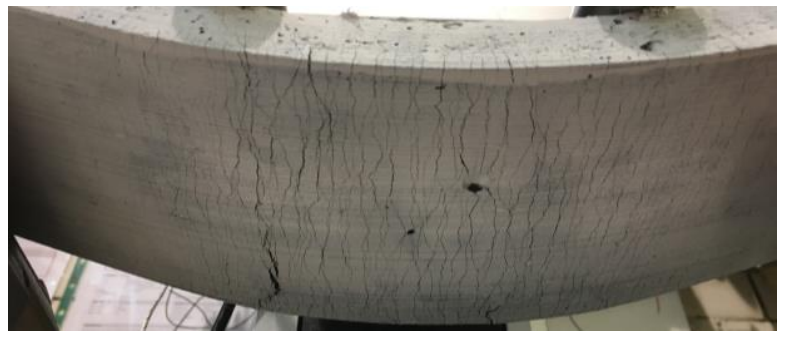

(b) Bottom view of microcracks.

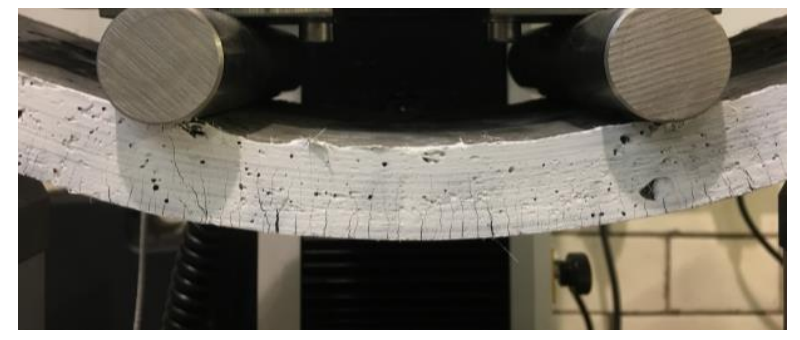

(c) Front view of microcracks.

Fig. 9. Typical failure mode and microcracks formed over the tensile side of SHGC specimen under four-point bending.

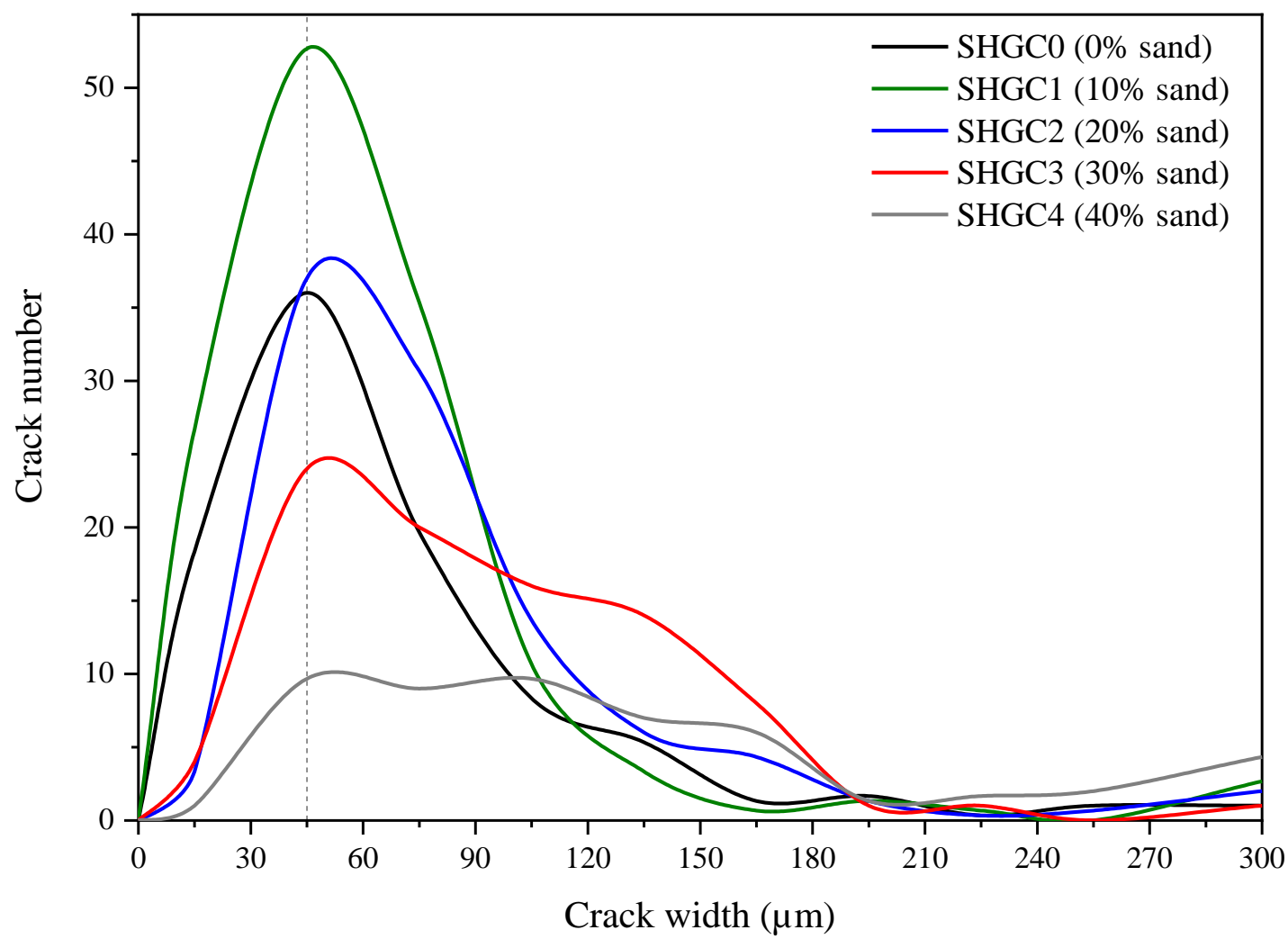

Fig. 10. Effect of sand content on crack number and crack width of SHGC specimens under fourpoint bending. 


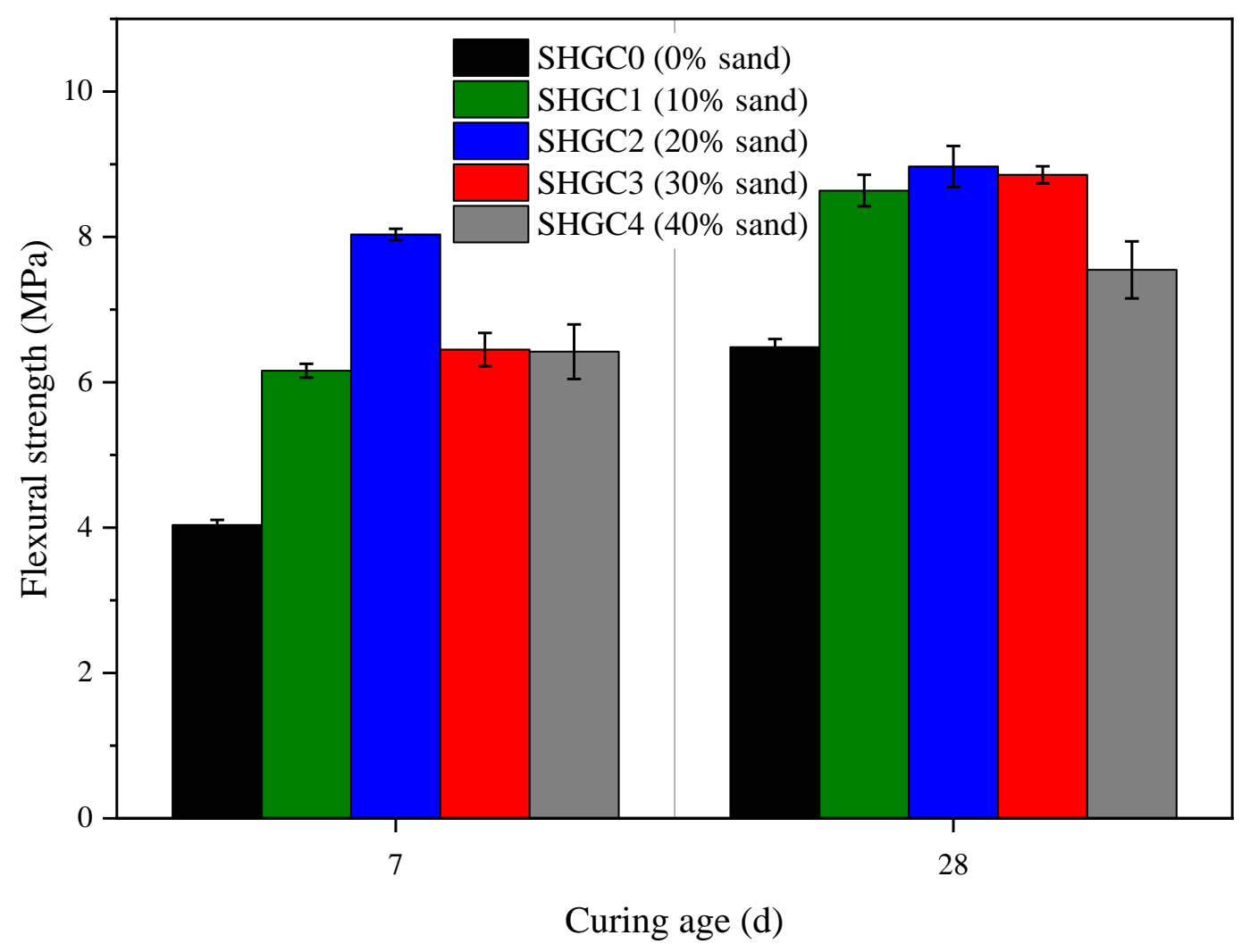

Fig. 11. Effect of sand content on flexural strength of SHGC specimens at $7 \mathrm{~d}$ and $28 \mathrm{~d}$.

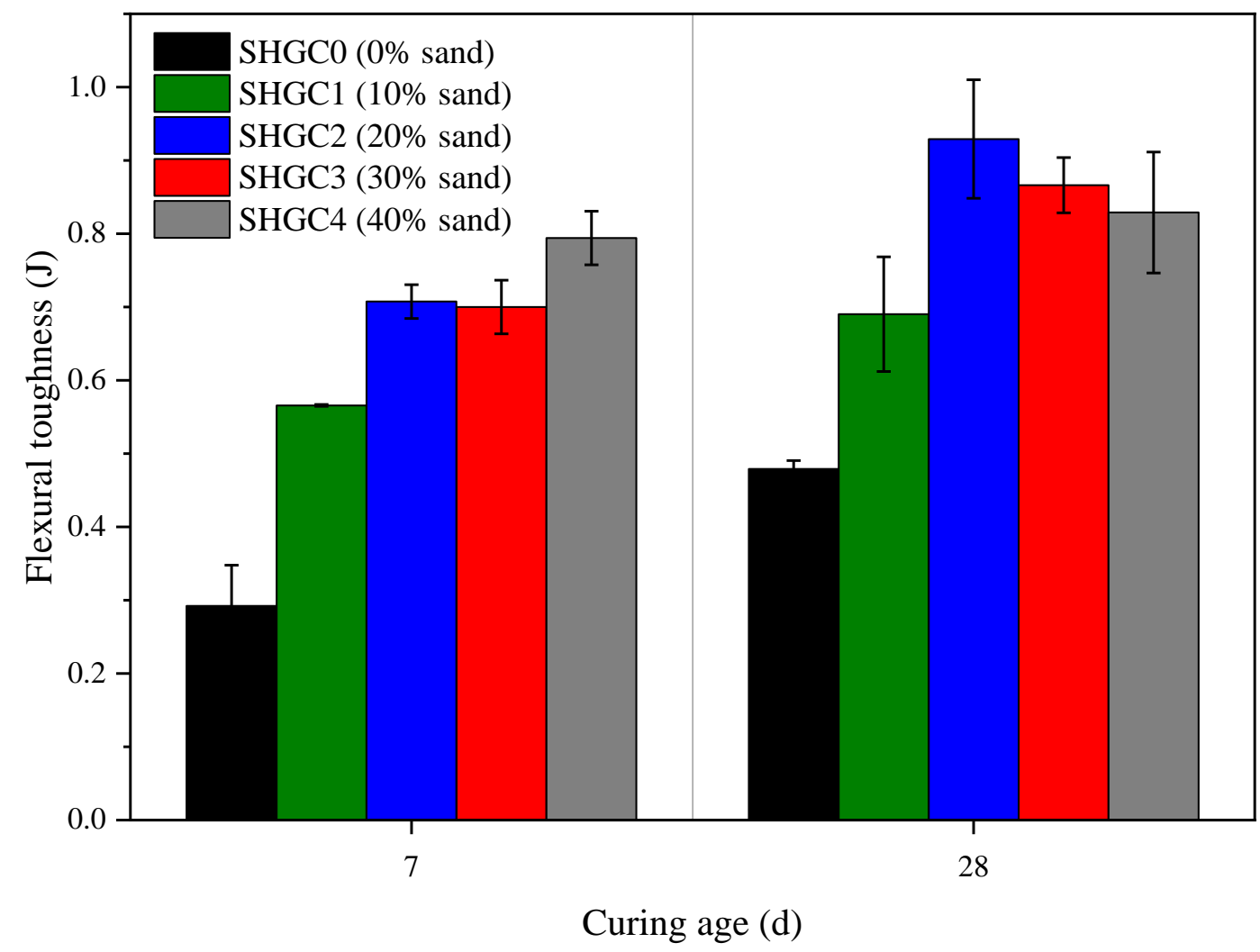

Fig. 12. Effect of sand content on flexural toughness of SHGC specimens at $7 \mathrm{~d}$ and $28 \mathrm{~d}$. 


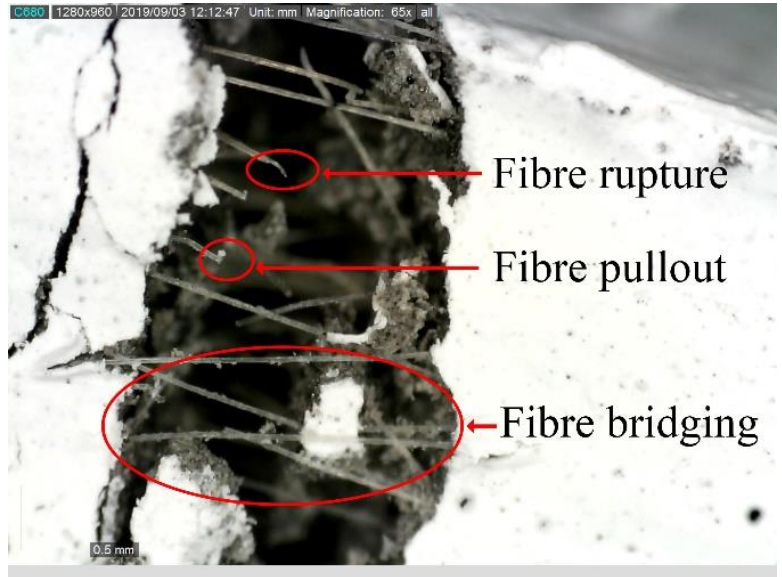

(a) Fibre toughening mechanism

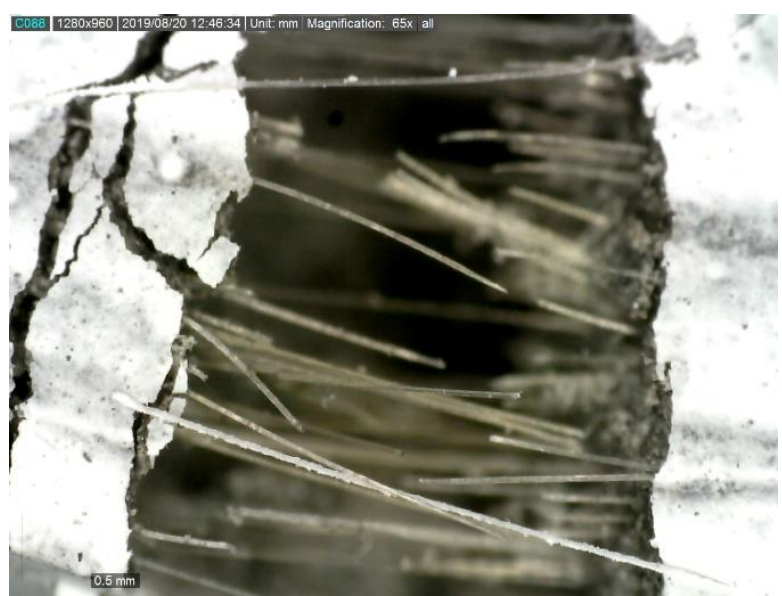

(c) Fibre pullout

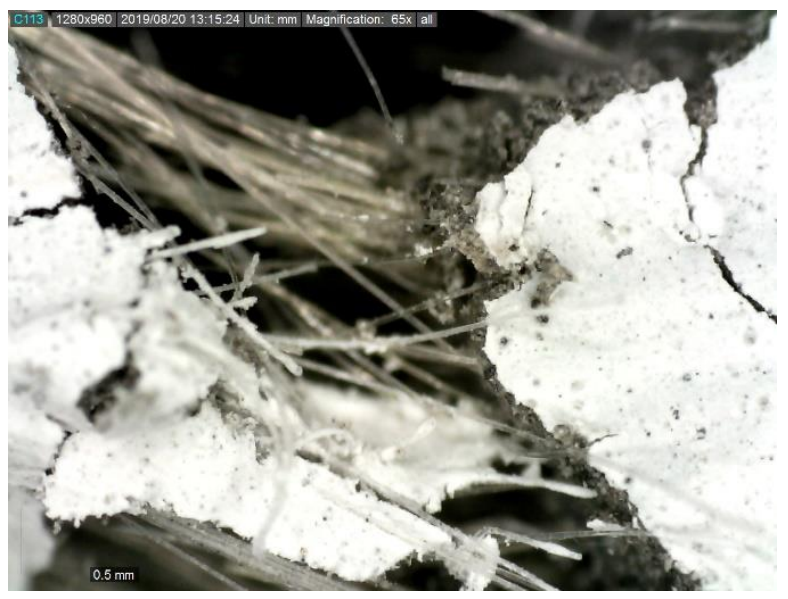

(e) Fibre corrugation

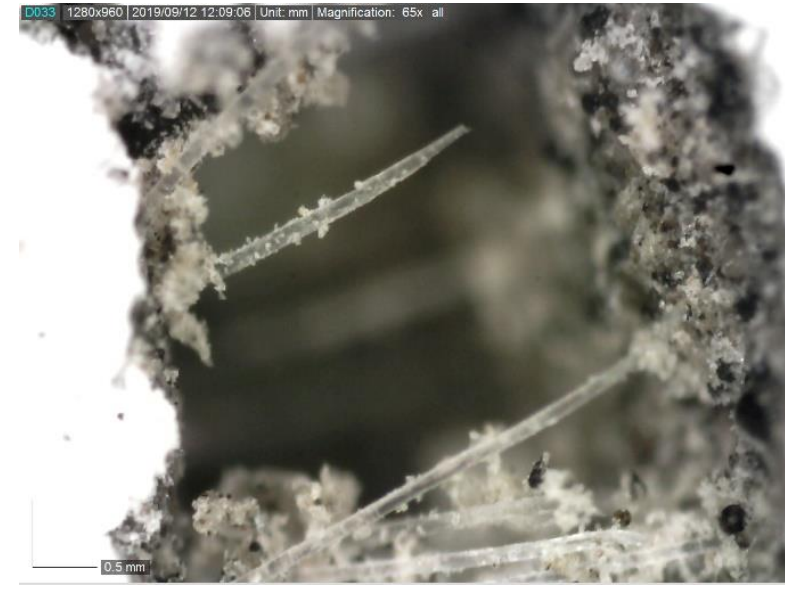

(b) Fibre rupture

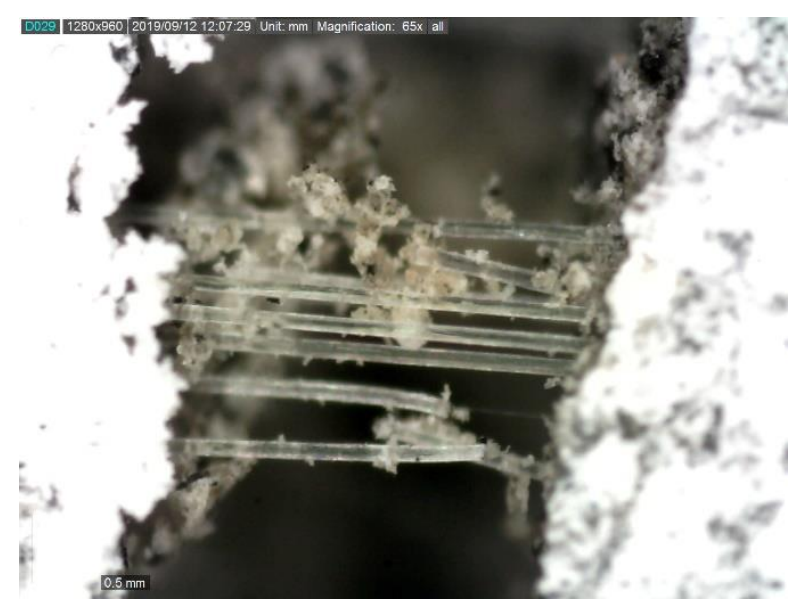

(d) Fibre bridging

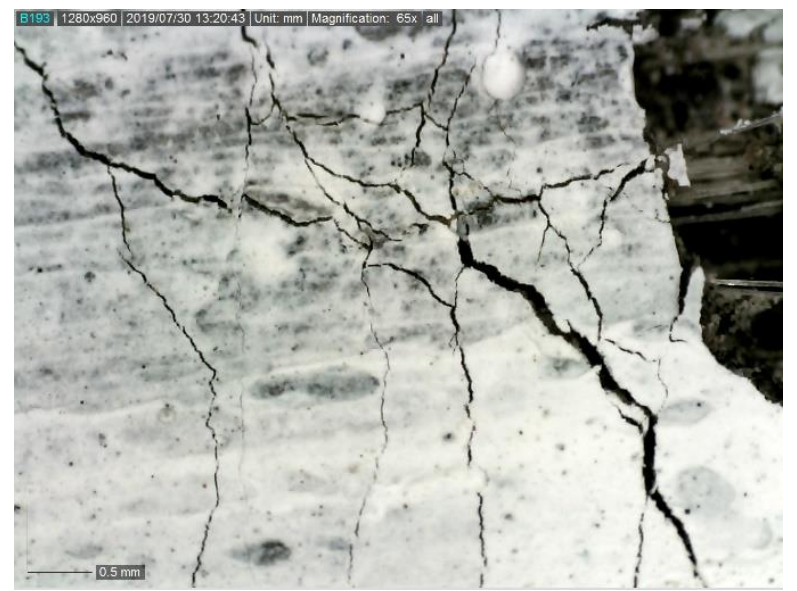

(f) Crack deflection and branching

Fig. 13. Toughening mechanisms of SHGC specimens. 